Volume 13, Issue 2 (Summer 2021)

\title{
Overlay Videos for Quick and Accurate Watermark Identification, Comparison, and Matching \\ Creating and Using Overlay Videos
}

C. Richard Johnson Jr., William A. Sethares, Margaret Holben Ellis

Recommended Citation:

C. Richard Johnson Jr., William A. Sethares, Margaret Holben Ellis, "Overlay Videos for Quick and Accurate Watermark Identification, Comparison, and Matching," Journal of Historians of Netherlandish Art 13:2 (Summer 2021)

DOI: $\underline{10.5092 / \text { jhna.2021.13.2.1 }}$

Available at https://ihna.org/articles/automated-watermark-identification/

Published by Historians of Netherlandish Art: https://hnanews.org/

Republication Guidelines: https://ihna.org/republication-guidelines/

Note: This PDF is provided for reference purposes and does not contain all the functionality and features of the online publication. Illustrations follow the text. This PDF provides paragraph numbers as well as page numbers for citation purposes.

ISSN: 1949-9833 


\title{
Overlay Videos for Quick and Accurate Watermark Identification, Comparison, and Matching
}

\section{Creating and Using Overlay Videos}

\author{
C. Richard Johnson Jr., William A. Sethares, Margaret Holben Ellis
}

Identifying, comparing, and matching watermarks in pre-machine-made papers has occupied scholars of prints and drawings for some time. One popular but arduous approach is to overlay, either manually or digitally, an image of the watermark in question with its presumed match from a known source. For example, a newly discovered watermark in a Rembrandt print might be compared to a similar one reproduced in Erik Hinterding's Rembrandt as an Etcher (2006). Such an overlay can confirm the pair as identical, i.e., as moldmates, or reveal their differences. But creating an accurate overlay for two images with different scales, orientations, or resolutions using standard image-manipulation tools can be time consuming and, ultimately, unsuccessful.

Part One of this article describes advances in the emerging field of computational art history, specifically the development of digital image processing software, that can be used to semi-automatically create a reliable animated overlay of two watermarks, regardless of their relative "comparability." Watermarks found in the prints of Rembrandt van Rijn (16061669) are used in three case studies to demonstrate the efficacy of user-generated overlay videos.

Part Two discusses how searching for identical watermarks, i.e., moldmates, can be enhanced through the application of a new suite of software programs that exploit the data calculated during the creation of user-generated animated overlays. This novel watermark identification procedure allows for rapid, confident watermark searches with minimal user effort, given the existence of a pre-marked library of watermarks. Using a pre-marked library of Foolscap with Five-Pointed Collar watermarks, four case studies present different categories of previously undocumented matches 1) among Rembrandt's prints; 2) between prints by Rembrandt and another artist, in this case Jan Gillisz van Vliet (1600/10-1668); and 3) between selected Rembrandt prints and contemporaneous Dutch historical documents. 


\section{Introduction: The Fascination and Frustration of Watermark Research}

1 It is exciting to discover an exact match of two watermarks found in historical pre-1800 European papers. Identical papers-moldmates-formed from the same papermaking mold imply that the papers share a narrow range of dates and a specific place of production. In practice, however, manipulating watermark images for comparison is rarely straightforward, especially when their images differ in scale, orientation, or resolution. For example, radiographs and transmitted-light photographs of watermarks are typically not reproduced either in books or online at the same scale as the watermark in question, making comparison of the two difficult whether performed manually, using actual films, or digitally, using photo manipulation tools such as Photoshop. Since confirmation of moldmates depends upon the precise alignment of all their details, including chain lines and laid lines, transparent overlays are preferred. This paper presents a computational method that allows users to create reliable and animated overlay videos of the watermarks, regardless of their degree of "comparability."

2 To provide context for the development of this dynamic visualization technique, a brief review of relevant advances in computational art history follows.

\section{Visualizing, Comparing, and Matching Manufactured Patterns in Supports of Artworks}

3 Watermark comparison and matching depends on the visualization of patterns: the watermarks, chain lines, and laid lines that are manifest in the paper itself as a result of the manufacturing process. Chain lines, as illustrated in figure 1, are the impressions left by the vertical wires anchoring the more closely spaced horizontal laid wires, which comprise the porous surface of the papermaking mold. The chain lines are typically about one inch apart and are generally equally spaced across the mold. The uniform spacing of the laid lines is critical for achieving an even thickness for each sheet of paper remaining on the surface of the mold after it has been scooped into a vat of aqueous pulp and the water has drained away. The watermark is a wire shape of a recognizable pattern that can be an identifying mark for the manufacturer or the enduse of the paper. Sheets of paper made on the same mold are called moldmates. Because each mold was handmade, the manufactured pattern it produced was unique.

4 Manufacturers' patterns exist in many different materials that have been used as supports for works of art. Some patterns, such as those displayed in woven fabrics, are recognized as idiosyncratic and have been used to differentiate the canvas supports of paintings. Until recently, this assessment was done exclusively by eye, using a standard measuring template. With developments in computational art history, manufactured patterns found in supports of works of art can now be visualized more extensively and accurately and compared using imageprocessing software. Below are examples of such computer programs applied to the manufactured patterns found in three different substrates: pre-1900 canvases prepared with lead white grounds; early twentieth-century silver gelatin photographic papers; and pre-1800 European laid paper. 


\section{PRE-1900 CANVAS}

5 X-radiographs of pre-1900 traditional European easel paintings on canvas often reveal variations in the thickness of the lead white ground used to prepare the raw canvas for painting. The coating is thicker, and therefore more radio-opaque, where it accumulated between the interstices of the canvas threads than where it lies on top of them. This discovery led to the practice of "thread counting," in which an image of sufficient resolution and clarity seen through a magnifying viewer allows for the manual counting of the number of threads per centimeter. Between 1500 and 1900, the manufacture of European canvas on a loom resulted in a bolt or roll that produced consistent warp and weft thread counts close to their averages. Thus, two canvases with substantially different average thread counts cannot be from the same original roll. The Rembrandt Research Project, founded in 1968 to assess the validity of the attribution of paintings to Rembrandt van Rijn, was the first major project to make extensive use of manual thread counting. ${ }^{3}$

6 Thread counting by eye was also used with great success to virtually reassemble a twenty-meter roll of jute with a very low thread count (around six threads per centimeter) used by Vincent van Gogh and Paul Gauguin during their stay in southern France. The analysis confirmed that two of the paintings created on the inexpensive jute were by Van Gogh, although their attribution had been doubted due to their unusual brushwork. ${ }^{4}$ This discovery stimulated interest at the Van Gogh Museum in performing further thread counts of paintings by Van Gogh. Given the approximate periodicity of thread spaces, a computational method was devised that can count the number of threads in small squares across the entire surface of a painting. Visualizationscalled weave maps - of the warp and weft thread counts use a color bar to indicate the thread count. ${ }^{5}$ These weave maps display stripes that indicate adjacent groupings of slightly different density that continue through the breadth and width of an original canvas roll. These striped weave maps essentially serve as a bar code for identifying pieces of canvas cut from the same roll-called "rollmates." Weave maps have now been computed for hundreds of Van Gogh paintings, resulting in a deeper understanding of the chronology of the artist's oeuvre. ${ }^{6}$

7 The discovery of rollmates among paintings on canvas by other artists has resulted in substantive art-historical insights. ${ }^{7}$ The first comprehensive study of all paintings on canvas by a single artist, Johannes Vermeer (1632-1675), revealed an unexpected number of rollmates-five pairs and one quartet-in thirty-four extant paintings, offering new insight into dating, authentication, and potential pendant pairs. ${ }^{8}$ The set of tools used to complete this work included a suite of free programs that facilitated manual counting and weave map creation. ${ }^{9}$ Alternatives to the basic algorithm first used in these Van Gogh and Vermeer studies have been proposed. ${ }^{10}$ 


\section{EARLY TWENTIETH-CENTURY PHOTOGRAPHIC PAPER}

$8 \quad$ Photographers have traditionally selected photographic papers according to their textures and finishes. Consequently, manufacturers of photographic paper produce a variety of coated papers having a variety of impressed textures. As noted in an essay by Paul Messier in the companion book to the exhibition Photographs from the Thomas Walther Collection, 1909-1949 at the Museum of Modern Art in 2014-2015, "Measuring texture required something new. As part of the Walther Collection research project, the 'Historic Photographic Paper Challenge' was initiated to invent new methods for characterizing and indexing the textures found on gelatin silver photographs." ${ }^{11}$ Similar texture analysis for paper classification has been extended to inkjet papers $^{12}$ and wove papers. ${ }^{13}$

\section{PRE-1800 EUROPEAN LAID PAPER}

9 Chain line intervals (see fig. 1) have long been recognized as a forensic marker in laid paper analysis. ${ }^{14}$ The measurement of chain spaces in a sheet of paper is recommended in the International Associations of Paper Historians' "International Standard for the Registration of Papers with or without Watermarks." ${ }^{\prime 5}$ Manual measurement is quite tedious and time consuming, however, so computational methods for measuring chain line intervals offer an alternative approach. Researchers have used various schemes to study chain line space patterns in Rembrandt's prints. ${ }^{16}$ For example, one computer-based method requires only a few marks by the user to locate automatically the chain lines crossing a test line traversing the sheet. ${ }^{17}$ This software produced a ranked list of possible moldmates in hundreds of Rembrandt prints. All known moldmates (because of their matching watermarks) were among the most highly ranked matches. This top group also included chain line patterns that were clearly not moldmates, since they had different watermarks. This result is attributable to the small shifts in chain spaces across a sheet and the measurement tolerances that are achievable with the limited resolution and clarity of typical radiographic images of antique laid paper. Images with more chain spaces available for comparison produced fewer top-ranked matches that were not moldmates. The basic result is that, while chain space patterns must match in moldmates, the matching of chain space patterns alone is not an indicator of moldmate status. ${ }^{18}$

10 Currently radiographs of laid paper typically do not allow for the counting of laid lines per centimeter. This is partly because the standard resolution used to scan analogue radiographs does not provide an adequate number of pixels across the width of the laid line. Our experience suggests that a resolution of 600 pixels per inch or more is needed. Another cause is the tendency of digital radiography to use an intensity setting calibrated to penetrate surface materials across the entire sheet of paper. This can result in a very dark, low-contrast image. When the contrast is improved - as, for example, with histogram equalization-the laid lines lose clarity. Consequently, even though laid line frequency is considered a useful indicator of the particular mold used in paper production, ${ }^{19}$ this forensic has not been collected systematically. However, for drawings and manuscripts, transmitted-light and surface photography of sufficient resolution can provide images in which laid lines are visible and 
countable. ${ }^{20}$ Laid line counting is similar to canvas thread counting, so algorithms for the latter have been adapted for the former. ${ }^{21}$ While the laid line density maps do not result in the striped patterns of canvas thread counts, they can be used to distinguish sheets that are not moldmates. Attempts to automate moldmate matching from laid line density maps are underway.

11 The successful application of the software that led to the determination of canvas rollmates, textured photographic paper classifications, and laid line density maps suggests that manufactured pattern recognition may be considered a form of computational connoisseurship. ${ }^{22}$

\section{Part One: Watermark Comparison and Matching}

12 While all three inner structural features of pre-1800 European laid paper (chain lines, laid lines, and watermarks) can be used to identify moldmates, the current feature of choice is the watermark, along with its occasional companion, the countermark. ${ }^{23}$ The first step is to identity the watermark type by consulting printed and online catalogues of watermarks. The website of the International Association of Paper Historians includes an extensive list of printed catalogues of watermarks and a separate one with links to more than twenty online catalogues. ${ }^{24}$ The latter includes the Bernstein Consortium's "The Memory of Paper," which is a portal to forty-two watermark databases containing more than 254,000 watermarks. Identifying a generic watermark type such as an eagle, foolscap, or flower is usually accomplished quickly and easily by a human viewer. However, it is far more challenging to discern the subtle differences between two watermarks of the same type. For example, are the number of talons the same from one eagle to another; are both foolscap collars embellished with five balls; does either leaf intersect a chain line? The correlation of such details can result in paper moldmate and twin matches, which can further inform art-historical and codicological questions. ${ }^{25}$ As noted on the website of the Dutch University Institute for Art History in Florence, "Datable paper may provide insights in a given paper brand used by an artist and could help to establish a chronology of works, verify authenticity, and highlight workshop practices." ${ }^{26}$ Past approaches to searching for matches and a possible new option are described in the second part of this article.

\section{Watermark Comparison and Matching in Rembrandt's Prints}

13 Over the past forty years, watermark matching has become the primary method used to establish the chronology of Rembrandt's prints. The work begun by Nancy Ash and Shelley Fletcher in 1981 established that the identification of watermarks makes it "possible to distinguish the early impressions of Rembrandt's etchings from the reprints he made later, and also to date those different editions fairly precisely." ${ }^{\prime 27}$ A ream (or less) of paper purchased by Rembrandt as an artist-printmaker would typically include many moldmates, sheets manufactured at the same time. Given Rembrandt's presumed rate of production, this paper usually would be transformed into prints over the period of a few months. Hinterding estimates that Rembrandt purchased, on average, approximately six batches of paper per year during his active period as a printmaker, 
from 1626 to $1665 .{ }^{28}$ Consequently, prints exhibiting identical watermarks would have been produced in a discrete time frame. A group of prints from different plates on papers that display the same watermark can be considered to have the same creation date-that is to say, the same year in which the impressions were made. In a group of prints with the same watermark, Hinterding used the print with the latest date inscribed in the plate as the key to date the whole group.

Two criteria were used for dating a group of impressions on the same paper. The first is whether the group contained early or rare states. If it did, that was almost invariably the most recent print, the one with the latest date, which was then used as a reference point for dating the entire group.... In addition, almost all impressions were assessed for quality, and this often made it possible to arrive at a plausible date for a group as a whole even if it contained no early or rare states. ${ }^{29}$

14 This logic underlies the chronology developed by Hinterding in his catalogue of more than five hundred distinct watermarks, or just over 250 watermark and twin pairings, ${ }^{30}$ found in the prints of Rembrandt van Rijn (see Case Study One for an explanation of twins). In his chronology, he is able to date 105 of these groups confidently. From this chronology he has developed a sense of the ebb and flow of Rembrandt's print production and its relationship to the events in his life and his development as a printmaker.

15 Hinterding's is a comprehensive catalogue classifying the different watermarks in a single artistprintmaker's works on pre-1800 laid paper. ${ }^{31}$ Classifying the watermarks into hierarchical type, variants, and sub-variants, based on ever more specific visible features shared by the resulting distinct groups at each level, allows for the construction of a decision tree, with yes/no questions providing a quick path to classifying a watermark of interest. ${ }^{32}$ In this model, the watermark being identified is compared visually with an illustration of the selected classification from the third volume of Hinterding's catalogue in order to confirm their moldmate status. The tools introduced here for producing an overlay video greatly increase the precision and confidence of a visual confirmation of moldmate status.

16 Watermark analysis was recently used to trace the provenance of printing plates in the highly regarded exhibition catalogue Young Rembrandt. ${ }^{33}$ The start date for the creation of a drawing of Rembrandt's father was established by matching its watermark to that in another drawing with an accepted date. ${ }^{34}$ Use of papers with the same watermark was also considered evidence of the close working relationship between Rembrandt and the printmaker Jan Gillisz van Vliet. ${ }^{35}$ Finally, watermark analysis of the different states of a print revealed where printings occurred for a plate Rembrandt began in Leiden and finished in Amsterdam. ${ }^{36}$ 


\section{Creating Overlay Videos for Watermark Comparison}

17 Two new user-friendly computational tools can be used to create an animated overlay of two similar watermarks for comparison and matching regardless of their different scales, orientations, and resolutions. ${ }^{37}$ Briefly, a simple point-and-click tool (watermarkPointMarker) allows the user to mark a numbered sequence of precisely locatable points on both watermark images. Examples of precisely locatable points or "tie points" might be where a flower stem crosses a chain line, where two wires of the watermark intersect in an acute angle, or the tip of each point of the crown that surmounts an eagle. The human user, who designates and numbers the points to be compared, performs this step. Hence, the procedure is "semi"-automated..$^{38}$ This point marking takes only a few minutes and creates data files utilized by the second software tool, visualizeOverlays, which optimally aligns the two sets of marked points. It then assembles a looping video in which one of the aligned watermarks transitions from fully visible to invisible, while the other watermark makes the opposite transition from invisible to visible. ${ }^{39}$ This makes dramatically and instantly clear any differences between the watermarks and the surrounding chain line intervals.

18 Indeed, overlays remain the gold standard for validating identical watermarks in the papers of Rembrandt's etchings. When confirmation overlays were first advanced by Ash and Fletcher, the originators of the classification for Rembrandt's watermarks, ${ }^{40}$ and later exploited by Hinterding,41 a method for readily creating an accurate overlay did not exist. These new image processing methods address that lack. Three examples of the utility of this new toolset are provided below.

19 The first example is an overlay video for two very similar but different watermarks that dynamically and quickly demonstrates their barely perceptible differences. The second example illustrates the comparison of a full watermark with a fragment, an otherwise fraught situation requiring confirmation that the visible portion of the watermark is dissimilar from other closely related possibilities. When the overlay also includes the chain lines near the watermark, as in the example presented here, their matching intervals can reinforce moldmate status. The third example is a match between a watermark in a Rembrandt print and a drawing by his student Ferdinand Bol (1616-1680), done after Bol had left Rembrandt's tutelage. This demonstrates the utility of the overlay software in expanding the universe of "Rembrandt" watermarks to include drawings, as well as prints, by Rembrandt and his circle. Each example includes a link to the associated looping overlay video.

\section{CASE STUDY ONE: AN OVERLAY VIDEO COMPARING SIMILAR WATERMARKS}

20 Figures 2 and 4 shows two states (B78iii and B78ii) of a Rembrandt print and their respective watermarks (figs. 3 and 5), which Hinterding's catalogue lists as moldmates. ${ }^{42}$ The two watermarks are marked in the same order at the same precisely locatable points in figures 6 and 7. Slight differences in this overlay video distinguish the two watermarks (fig. 
10). In particular, look closely at the right edge of the shield, the vertical chain lines, the sides of the central leaf in the fleur-de-lis, and the alignment of the bottom tip of the fleur-de-lis and the top tip of the shield. These two watermarks are the two Strasbourg Bend twins D'.a.a and D'.a.b. This distinction was noted in the construction of the decision tree for the Strasbourg Bend type by the WIRE Project at Cornell ${ }^{43}$ provided in figure 8 . The path to Strasbourg Bend subvariant D.a is isolated in figure 9. The overlay video provides compelling confirmation of their differences.

21 As the two Strasbourg Bend watermarks in this case study demonstrate, twin watermarks can be quite difficult to distinguish without a precise overlay. Until the 1800 s, laid paper was made using a pair of molds in rotation to increase the efficiency of production. While the paper was draining from one mold, a sheet made just before was being removed from the alternating "twin" mold. Sheets made with this pair of molds, each having similar watermarks, were destined to end up in the same ream of paper. ${ }^{44}$ The molds were the same size and consequently produced same-sized sheets, and the handmade watermarks were made to appear the same. Sometimes the similarity is imperfect, and the paper made on each mold is easily distinguished by visually comparing the watermarks. Other twin molds can have extremely close watermarks, as in this case study. Because papers made on the twin molds would have been packaged in the same ream of paper, they would have been purchased together and used in the same printmaking sessions. Therefore, impressions made from the same state of a plate that have laid paper supports with very similar watermarks can be used to identify twin molds. In terms of dating, the impressions made on twin molds can be assigned the same date. ${ }^{45}$

\section{CASE STUDY TWO: AN OVERLAY VIDEO SUPPORTING WATERMARK FRAGMENT IDENTIFICATION}

22 The WIRE decision tree is currently limited to the identification of full watermarks, since the distinguishing features are found throughout them. ${ }^{46}$ However, a sizeable number of watermarks in Rembrandt's prints are fragments. This occurs because many of Rembrandt's prints are much smaller than the full sheet of paper as manufactured and, therefore, encompass only a fragment of the watermark or none at all. Further, many Rembrandt prints have been trimmed down to the size of the plate imprint, losing even more of the surrounding sheet.

23 An overlay video generated by our new toolset can be used to provide an identification of moldmates or, conversely, confirmation that a watermark and a fragment are not moldmates, as illustrated in the Foolscap with Five-Pointed Collar watermark and fragment in figures $11,12,13$, and 14 .

24 The marked watermarks for this example appear in figures 15 and 16. Note that figure 16 was black-white inverted in the marking software before marking, so that both marked watermarks would have white wires (seen in fig. 17). 
25 This match also has art-historical implications. For a long time, The Artist's Mother in Widow's Dress and Black Gloves was considered a print by Rembrandt. Eventually, it was attributed to a pupil of Rembrandt, although the identity of this pupil remains a matter of debate. While the moldmate match is to a paper used by Rembrandt well after the plate date, the plate date can be used to help identify the pupil who created the print. ${ }^{47}$ This moldmate match also could be cited to influence the debate about the degree to which Rembrandt shared his printmaking techniques with his pupils.

\section{CASE STUDY THREE: MOLDMATES IN A REMBRANDT PRINT AND A BOL DRAWING}

26 Another use of the new toolset is the confirmation of moldmates from beyond the oeuvre of Rembrandt's prints. The print from the Metropolitan Museum of Art (fig. 2a) can be juxtaposed with a drawing by Rembrandt's pupil Ferdinand Bol, made after Bol had departed Rembrandt's studio (fig. 18). Compare the Strasbourg Bend watermark in the print from the Metropolitan Museum of Art (fig. 3a) to a Strasbourg Bend watermark in the Bol drawing (fig. 19). The marked watermarks appear in figures 6a and 19a. ${ }^{48}$ The exact match of these Strasbourg Bend watermarks can be observed in figure 20 .

27 Hinterding dates the use of paper with the Strasbourg Bend D'.a watermark as 1653 and notes thirty-three impressions using this paper from four different printing plates. ${ }^{49}$ Twenty-two of the impressions are of states i through iv of The Three Crosses (B78), which include the two impressions illustrated in figures 2 and 4 . The Bol drawing in figure 19 is a design submitted for a competition to execute paintings in the Amsterdam City Council Chamber. This drawing was attributed to Rembrandt until 1926, when its link to the decoration of the Amsterdam Town Hall was recognized. This results in a date of about 1655, which corresponds to the dating of Rembrandt's use of paper with the same watermark. ${ }^{50}$

28 Around the same time, Bol also submitted designs for two paintings to hang in the Burgomaster's Council Room of the Amsterdam Town Hall. His design for The Steadfastness of Caius Fabricus Luscinus received the commission. Bol's drawing is dated $1652-1655 .{ }^{51}$ The paper support contains a countermark consisting of the letters IHS (and a small crown and cross). This and the matching countermark IHS E.b in Hinterding's 2006 catalogue appear in figures 21 and 22. Their overlay GIF shows an exact match (fig. 23). Hinterding's catalogue lists only one impression with IHS E.b and dates it ca. $1658 .^{52}$

29 These two matches across artists and genres, based on watermarks in the paper supports of two Bol drawings and two Rembrandt prints from the mid-1650s, stimulate contemplation. Do these uses of paper moldmates indicate the general availability of the same papers throughout the Netherlands? Or do these two matches suggest that Rembrandt and Bol had a close collaboration in the 1650s? The latter suggestion is supported by other evidence of shared paper use for print supports. ${ }^{53}$ 


\section{Part Two: Enhanced Watermark Comparison and Matching Using Searchable Libraries}

30 The first part of this article described the typical processes of identifying a watermark type and then creating an animated overlay for comparison and matching with others of the same type. In the looping video, one of the aligned watermarks transitions from fully visible to invisible while the other watermark simultaneously transitions from invisible to visible. Animated overlays appeal to the close-looking skills of the user and are more convincing than their supporting numerical codes and graphs.

\section{Comparison of One Watermark to a Library of Many Similar Watermarks}

31 When the goal is to compare one watermark to many others of the same type, the task of creating a video for each pairing becomes overly time consuming. For example, candidates for matching foolscap watermarks in Rembrandt prints, even when limited to those having fivepointed collars, number more than forty-representing the number of images available for comparison, not how often this particular watermark is found. ${ }^{54}$ It has been noted that more than 250 Rembrandt prints contain a Foolscap with Five-Pointed Collar watermark. ${ }^{55}$

32 The concept of comparing one watermark image to a library of many similar watermark images is not new. Numerous efforts have been undertaken to digitize and categorize the tens of thousands of different watermarks in fifteenth- to eighteenth-century European laid papers that appear in artists' prints, drawings, and sketchbooks; composers' autograph scores; authors' handwritten manuscripts; printed books; and historical documents. ${ }^{56}$

33 Searching through these databases for a potential watermark match can be a laborious process, especially since many of the images are difficult-to-decipher rubbings and tracings of watermarks. The website of the Centre for the Study of the Renaissance at the University of Warwick has a page on watermark databases that includes links to various online databases along with incisive commentary on their scope, taxonomic search descriptors, and limitations in identifying exact matches (or moldmates). It includes the observation: "What none of these systems allow for is the computerized search of the images themselves, which would clearly be preferable." ${ }^{n 7}$

34 Digital image processing engineers and computer scientists have sought to automate computerbased watermark identification fully by creating a program that can search a large database for images, without human intervention, to produce the most similar matches. Some schemes are based on digital image processing techniques. ${ }^{58}$ Others use machine learning and deep neural networks. ${ }^{59}$ This task is technically difficult. A recent blog post from the UK National Archives succinctly describes new systems under development that combine advanced imaging techniques, image processing, and visual search capabilities. ${ }^{60}$ The techniques described require 
either advanced image processing skills rarely possessed by the target community of art historians, conservators, and curators, or in-house imaging systems available in only top-tier museums. They are typically applied more successfully to collections of images (such as handtraced watermarks) that suppress extraneous image components not associated with the watermark. Unfortunately, tracings usually lack the fine detail needed to confirm moldmates.

The goal of such fully automated schemes is limited to finding similar watermarks, rather than moldmates. For example, when given an eagle watermark, they will identify other eagles. Such systems can return plausible matches. The problem is more difficult to approach if we begin with two watermarks of the same type (e.g., two eagles or two flowers) and try to determine if they are exact matches, plausible matches, or genuinely different. Variants of a given watermark type are only subtly different, and the differences tend to be idiosyncratic and hence not easily captured by example-based statistical learning methods.

36 A concern in the user community is that a fully automated system may not be able to articulate in terms of visible features why the selected candidates were chosen as matches. A watermark selected as a match from a library, by contrast, would be based on observable criteria, such as specific features, rather than mathematical properties not easily translated into a visual guide for the intended user. The traditional preference among scholars is for a tool that allows the expert to observe and assess the degree of sameness between watermarks-preferably through an overlay, a process that takes advantage of the exceptional close-looking capabilities of this user community. This overlay procedure would need to work on images of different resolution, orientation, and quality (including partially obscured images). The precision required makes ineffective the tracings and rubbings that are the core content of most watermark catalogues.

37 The logical next step of comparing one watermark image to all available images of that watermark type can be semi-automated through the application of a new suite of software programs. As described above, the user again marks precisely locatable points, but this time according to a predefined sequence of points for that particular watermark type. As seen in figure 24, illustrating a Foolscap with Five-Pointed Collar watermark, eleven preselected points have been marked in the predefined numerical order. ${ }^{61}$ Fully automated software then scales, translates, and rotates the final point pattern to achieve the best fit for every image in a premarked library of Foolscap with Five-Pointed Collar watermarks. If a suitable match is detected, it is confirmed (or invalidated) with software that creates an overlay video.

38 One way of recognizing differences in watermarks within a certain type is to describe them in prose. For example, in figure 24 the right bell atop the jester's cap is misshapen, while in other variants it is perfectly round. Alternatively, our signal processing software marks the points, which are described semantically and mathematically, and selects the watermark image that has the closest alignment between their marked points. This type of search, however, presupposes that a library exists of known watermarks of the same generic type that have been pre-marked using the same set of precisely locatable points. 
39 If the marked points for watermark $\mathrm{A}$ are called $(a 1, a 2, \ldots, a n)$ and the corresponding points of watermark $\mathrm{B}$ are called $(b 1, b 2, \ldots, b n)$, the optimal alignment is given by linear mapping that takes $a 1$ as close as possible to $b 1, a 2$ as close as possible to $b 2$, and so on. The average error over all $n$ points is the "alignment error." When two watermarks truly match, the alignment error is small (typically about one pixel). When the two watermarks do not match, the alignment error is significantly larger. A detailed description of how alignment error is calculated is given in Appendix 3.

40 The computation of the alignment error is completed in minutes, and a list of the alignment errors is visualized as a bar graph (as in figure 25). If a match for the candidate watermark is found within the library, one bar will be substantially shorter than all of the others. On the other hand, if there is no bar clearly shorter than the others, it is likely that the watermark is not in the library, although it is also possible that the points have been marked incorrectly or out of sequence. We have introduced the marking template for each type to help forestall such marking issues. The user can then automatically create an animated overlay of the potential match, which serves as the ultimate check on the pair that has the smallest alignment error. ${ }^{62}$

\section{Searching for Foolscap with Five-Pointed Collar Watermarks in Rembrandt's Papers}

41 Four case studies demonstrate the potential usefulness of our semi-automated watermark identification system. Each example searches for a watermark type commonly found in Rembrandt's prints: a Foolscap with Five-Pointed Collar (fig. 26).

42 The Foolscap with Five-Pointed Collar is among the watermarks that appear most frequently in Rembrandt's prints; Erik Hinterding's 2006 catalogue Rembrandt as an Etcher includes more than forty different variations of this type. ${ }^{63}$ Hinterding's hierarchical classification labels start with capital letters A through $U$, each indicating a variant group with certain prominent visible features. The capital-letter variant designation is followed by one or two lowercase letters. The first lowercase letter designates watermarks in a subvariant category that possess a set of finer distinguishing features. The second lowercase letter is used to distinguish very similar watermarks with distinctions that are sometimes difficult to spot without very close looking. These are identified as twins, suggesting that they are from sheets of paper produced simultaneously with watermarks that were designed to be nearly identical. Thus, the watermarks in Hinterding's catalogue that are grouped into this variant-subvariant-twin hierarchy have labels such as F.b.b or K.a.a. The online Appendix 1 to this article includes marked images of forty-three of such watermarks that appear in a full (rather than fragmentary) version in volume three of Hinterding's catalogue ${ }^{.64}$

43 The most labor-intensive aspect of creating potential matches based upon alignment error calculations is pre-marking the examples of a given watermark type for the library. ${ }^{65}$ The following description of the precisely locatable points to be marked, in the prescribed sequence, for a Foolscap with Five-Pointed Collar watermark assumes that the jester is oriented as in figure 
26. If a defined point is obscured or does not appear because the watermark is fragmentary, an option exists in the software for skipping it. This maintains the labeling of subsequent points with their proper position in the sequence. The eleven precisely locatable points are:

1. top intersection of chain line to the left of the center of the watermark with the left peak of the foolscap ${ }^{66}$

2. top intersection of the chain line to the right of the center of the watermark with the right peak of the foolscap ${ }^{67}$

3. top intersection of the left chain line with the first (leftmost) collar point ${ }^{68}$

4. top intersection of the right chain line with the braid, including the bow, extending from the back of the head ${ }^{69}$

5. top intersection of the right chain line with the fifth (rightmost) collar point ${ }^{70}$

6. tip end of the first (leftmost) collar point, which is typically where it attaches to a ball (even though sometimes a ball is absent)

7. tip end of the second collar point

8. $\quad$ tip end of the third collar point

9. tip end of the fourth collar point

10. tip end of the fifth collar point

11. top intersection of the bottom of the post emerging from the ball at the end of the middle (third) collar point and the three roundels at the bottom of the watermark. These marked and numbered points are shown in figure $24 \mathrm{a}$.

44 The entire set of pre-marked watermarks can be seen in Appendix 1, which forms the library of Foolscap with Five-Pointed Collar watermarks. An unidentified Foolscap with Five-Pointed Collar watermark can be compared automatically after marking it at the same set of numbered points.

45 The results of the following case studies have a number of art-historical implications. Case Study Four identifies a watermark noted but not identified in Hinterding's 2006 catalogue. Case Study Five identifies the watermark in a print by printmaker Jan Gillisz van Vliet, who was a contemporary of Rembrandt, as a moldmate to one in Hinterding's 2006 catalogue. Case Study Six reveals a moldmate match between a watermark in a seventeenth-century Dutch document with one in a Rembrandt print. Finally, Case Study Seven illustrates how twin watermarks found in impressions of Rembrandt prints from the same plate can be used to identify batchmates in archives of historic documents, and conversely how moldmate connections can be established between prints from the same plate when both are found in a full-size broadsheet historical document with the same watermark or countermark.

\section{CASE STUDY FOUR: FOOLSCAP WITH FIVE-POINTED COLLAR WATERMARK IDENTIFIED}

46 The first watermark to be identified is figure $26 .{ }^{71}$ Its marked image appears in figure 24 . The numeration of each of the black dots with red centers appears in yellow to its left. This 
numerical sequence must be followed when marking each watermark so that the software can correctly identify the degree of alignment between them.

47 The bar graph seen in figure 25 was generated by the software described in Appendix 2; it compares the average errors of alignment against all forty-three marked examples found in the library (Appendix 1). A very short bar implies that an overlay video will likely reveal a very close match-that is, a potential moldmate match.

48 The shortest bar in figure 25, by far, is associated with K.a.a, which is the correct identification for the watermark in figure 26. This identification is confirmed by an overlay video (fig. 27). ${ }^{72}$ In Hinterding's 2006 catalogue, the watermark in B208iii at the Morgan Library \& Museum is listed as "not identified" because "no X-radiograph is available." 73 This confirmed K.a.a Foolscap with Five-Pointed Collar watermark can now be added to the tallies of impressions compiled by Hinterding and will add to the comprehensiveness of his data. ${ }^{74}$

\section{CASE STUDY FIVE: MATCHING WATERMARKS IN PRINTS BY REMBRANDT AND JAN GILLISZ VAN VLIET}

49 As a second example, consider a print by Jan Gillisz van Vliet, which contains a Foolscap with Five-Pointed Collar watermark that is marked in figure 28. The average alignment errors, calculated by comparing it with all of the marked watermarks in Rembrandt's prints in Appendix 1, are visualized in figure $29 .{ }^{75}$

50 The Foolscap with Five-Pointed Collar watermark K.e.a has the shortest bar. This identification of the watermark in figure 28 as a moldmate to Foolscap with Five-Pointed Collar K.e.a can be verified by its overlay video (fig. 30$){ }^{76}$

51 That a print by Rembrandt shares a moldmate with a print by Van Vliet raises some interesting questions. Jan Gillisz van Vliet was a printer based in Leiden in the period that Rembrandt began making prints before his move to Amsterdam, by 1633. Evidence of their collaboration in prints attributed to Van Vliet is supported by watermark analysis. ${ }^{77}$ The last dated prints by Van Vliet are from 1635. However, the date associated with Rembrandt's use of paper with the Foolscap with Five-Pointed Collar K.e.a. watermark is $1651 .^{78}$ This gap in dates raises new questions about the ownership of Van Vliet's plates. As more images are taken of a wider group of seventeenth-century Dutch printmakers, more of such moldmates can be readily identified with our new software. This will offer valuable new insights into artist interactions and paper production and distribution in the Netherlands in the seventeenth century. 


\section{CASE STUDY SIX: IDENTIFYING A WATERMARK IN A CONTEMPORANEOUS DUTCH HISTORICAL DOCUMENT}

52 The sixth example is drawn from the catalogue by Theo and Frans Laurentius, Watermarks

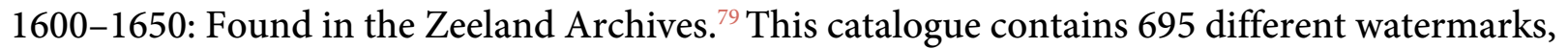
including seventy-two foolscaps, of archived historical documents. Catalogue entry number 483 is a Foolscap with Five-Pointed Collar watermark from a document used in The Hague in 1642, with the paper's origin listed as Angoumois. This corresponds to the area of Angoulême, located in southwestern France, renowned for its paper production since at least the sixteenth century. ${ }^{80}$ The marked image of this watermark (after inversion of its grayscale so the watermark wires are white) appears in figure 31.

53 The average alignment errors, from comparison with all of the marked watermarks in Rembrandt's prints in Appendix 1, are diagrammed in figure 32. The smallest average error is for the Foolscap with Five-Pointed Collar watermark H.b.a. The next-smallest bar for H.b.b is quite close, which is reasonable as H.b.b is the (not identical) twin of H.b.a. This identification of the watermark in figure 31 as Foolscap with Five-Pointed Collar watermark H.b.a is verified by an overlay video (fig. 33) ${ }^{81}$ In Hinterding's catalogue, the Foolscap with Five-Pointed Collar watermark H.b.a is noted as occurring in three impressions of B188iv, which are signed and dated $1642 .^{82}$ This date matches the date of catalogue number 483 in the Laurentius catalogue.

54 The correspondence of a Rembrandt watermark with one in an archived dated historical document used in The Hague adds evidence about the distribution of paper in the Netherlands in the seventeenth century. It also shows that connecting watermarks in prints to matching watermarks in dated historical documents can assist in dating impressions of prints.

\section{CASE STUDY SEVEN: IDENTIFYING A TWIN WATERMARK IN A CONTEMPORANEOUS DUTCH HISTORICAL DOCUMENT}

55 We continued examination of the seventy-two foolscaps in the Laurentius catalogue, focusing on papers with the following criteria: 1) recorded as used in The Hague in 1642; 2) origin listed as Angoumois; 3 ) containing a watermark similar to the Foolscap with Five-Pointed Collar watermark labeled with number 483 (found in the previous example to match the Foolscap with Five-Pointed Collar H.b.a). As all of the numbered watermarks in the Laurentius catalogue are distinct, and not moldmates, the presumption is that one of these watermarks with the same origin and date of use might have come from the same batch of paper and, therefore, be from the twin mold used in the production of the watermark 483. This search for such similar watermarks revealed two that are numbered, in Laurentius, 544a and 545a. ${ }^{8}$

56 The marked image (after inversion of its grayscale so the watermark wires are white) of watermark number 545a appears in figure 34. The average alignment errors from comparison with all of the marked watermarks in Rembrandt's prints in Appendix 1 are presented in figure 35. The bars in figure 35 for Laurentius watermark 545a form a pattern quite similar to that in figure 32 for Laurentius watermark 483. The principal exceptions are the alignment errors 
associated with the Foolscap with Five-Pointed Collar watermarks H.b.a and H.b.b in Hinterding's 2006 catalogue. The entry in figure 35 associated with H.b.b has the smallest average alignment error and is the only one with a value below 1 . The entry associated with H.b.a is the next-smallest.

57 The identification of the watermark in figure 18 as Foolscap with Five-Pointed Collar H.b.b is verified by an overlay video (fig. 36).$^{84}$ In Hinterding's catalogue, the Foolscap with Five-Pointed Collar H.b.b is noted as occurring in one impression of B188iv, which is signed and dated $1642{ }^{85}$ Because H.b.b occurs in the same print as H.b.a, they are designated by Hinterding as twins, with the second lowercase letters in their labels being "a" and " $b$." This implies that Laurentius watermarks 483 and 545a are from two twin molds used in the production of the same batch of paper.

58 The marked version of Laurentius 544a is shown in figure 37. The average alignment error bars appearing in figure 38, from comparison of Laurentius 544a with all of the marked watermarks in Rembrandt's prints in Appendix 1, do not exhibit any values less than one. The smallest values correspond, respectively, to Foolscaps with Five-Pointed Collar H.b.a and H.b.b from Hinterding's 2006 catalogue. That neither of these is a match is apparent from comparison with figures 31,34 , and 37 . The Laurentius 544a watermark lacks the ball at the end of the fourth collar point from the left that is present in both Laurentius watermark 483 and Laurentius watermark 545a. But could Laurentius 544a be a version of Laurentius 483 or 545a that has lost this fourth ball? Other visible distinctions between 544a, 483, and 545a dispel that notion. For example, the two circles atop the head of the joker, between the striped peaks in the foolscap that end in bells, are visibly larger in 544a than in 483 and 545a.

59 Recall that Laurentius watermarks 483, 544a, and 545a all have the same archive location (The Hague) and date of use (1642). Further, the prints with watermarks H.b.a and H.b.b in Hinterding's 2006 catalogue-which match, respectively, Laurentius 483 and 545a-were created with the same plate for printing impressions of B188iv. Consequently, the fact that the Laurentius watermark 544a has no match to any watermark in Hinterding's 2006 catalogue, but is quite similar to Laurentius watermarks 483 and 545a, has some interesting implications, given the assumption that the same paper available in Amsterdam was available elsewhere in the Netherlands in the seventeenth century. ${ }^{86}$ One possibility is that there is a Rembrandt print yet to be identified that has a watermark matching Laurentius 544a. The more likely situation is that the papers used by Rembrandt represent only a fraction of the papers imported into the Netherlands in the seventeenth century that were made on different molds. This is underscored by a quick scan of the seventy-two foolscaps in the Laurentius catalogue, which shows that over a third have no matches in Hinterding's catalogue. These observations suggest that studies of the watermarks in prints by other Dutch printmakers active in the seventeenth century will likely yield some matches to watermarks in Rembrandt's prints, as well as many watermarks not occurring in Rembrandt's prints.

60 There is one other benefit to be drawn from catalogues of watermarks found in archives of historic papers. Many of the historic papers are uncut broadsheets that include both a 
watermark in one half and a countermark in the other half. In the Laurentius catalogue, watermark and countermark pairs found in the same sheet of paper are labeled with the lowercase letters "a" and " $b$ " appended to the number of the watermark. The single-wired PR countermark in Laurentius 545b appears quite similar to the countermark PR.a in Hinterding's 2006 catalogue. Marked versions of the two countermarks appearing in figures 39 and 40 can be used to create an overlay video that confirms that they match (fig. 41). ${ }^{87}$ Not surprisingly, Hinterding's 2006 catalogue cites three occurrences of countermark PR.a in impressions of B188iv. ${ }^{88}$ This suggests that these three occurrences of PR.a are moldmates of the papers containing the Foolscap with Five-Pointed Collar H.b.b.

61 Case Study Seven matches a watermark in a dated historical document to a watermark known to be a twin of the dated historical document in Case Study Six. The twin status of these two watermarks in the archived historical documents is established by the fact that the two watermarks appear in impressions made by Rembrandt from the same plate. This dated historical document introduced in Case Study Seven was from a full broadsheet, and the countermark was also archived. This countermark is recorded in Hinterding's catalogue as appearing in impressions made from the same plate as the twin pair of Rembrandt prints in the third and fourth examples. This is significant because the Rembrandt prints in the third and fourth examples are from folios (i.e., half sheets), in which either the watermark or a countermark can appear, but not both. This provides evidence for dating the prints with the date of use recorded for the full-broadsheet historical document.

\section{Concluding Remarks}

62 This article began with straightforward instructions on how to create animated overlay videos to confirm or reject the moldmate status of two watermarks, regardless of differences in the scale, resolution, or orientation of their images. This software produces an optimal alignment of the two watermarks in terms of the sequence of marked points. By extension, watermark searches can be expanded across a library of watermarks of the same type as the watermark of interest, given that all are labeled at the same set of match points and in the same order. The user could label their watermark and use the software to compare to the location of match points across the watermarks in the similarly labeled group. The software could then provide a video of the top choice with the closest fit according to the optimization criteria used in our alignment software. This would allow the user to assess the fit visually in order to confirm or reject the match.

63 Building a comprehensive system would require a substantial effort to pre-label all the watermark types in Hinterding's catalogue. However, this possibility does hint at a path toward the goal of semi-automatic watermark identification within the works on paper of a single artist or a group of artists from a particular period.

64 The watermarks that have been identified above as occurring in the Rembrandt's prints by applying our new semi-automated watermark identification procedure offer a number of arthistorical insights. The breadth of the sources for these discoveries of moldmates and twins, 
which extend from Rembrandt's prints to those by another artist, and even beyond the realm of works of art on paper to historical documents, emphasizes the range of utility of the new tools presented here for the study of watermarked antique laid papers. The tools we introduce can be used to answer the tedious and labor-intensive process of determining exactness. The software can be applied to examine the possible match of a pair of watermarks, as described in Part One of this article, "Watermark Comparison and Matching"; to determine the existence of a match for a single watermark in a pre-marked library; or to find all of the cross-matches between two batches of appropriately marked watermarks of the same general type as in Part Two. As such, these tools can be used to build the libraries of marked images for future rapid watermark identification inquiries, as well as to search within the libraries once they are constructed.

65 Our intent is to advance the development of techniques needed for realistic computerized searches of large databases best suited to the needs of the user community of paper and art historians and conservators.89 These techniques will allow users to leverage fully their expertise and experience in close looking when performing this task. At the same time, we hope that our semi-automated watermark identification procedure will inspire digital image processing engineers and computer scientists to produce more sophisticated procedures for watermark identification, now an established field within digital art history.

\section{Appendix 1: Library of Marked Foolscaps with Five-Pointed Collar Watermarks}

66 Due to the large size of the library of forty-three marked watermarks that appear in full (rather than fragmentary) versions in volume three of Hinterding's catalogue, Appendix 1 is available for download here.

\section{Appendix 2: Description of Software Used to Mark, Rank Similarity, and Create Overlay Videos of Watermarks}

67 There are several steps in the procedure for testing the similarity/difference between watermark images. First, the corresponding points must be assigned using the program watermarkPointMarker, which has the graphical user interface shown in figure 42 . The watermark images are loaded in one by one and points are marked by the user through straightforward clicking. After all the points are selected, the snapshot button is used to save the data. This writes a series of files that are used in subsequent steps.

68 The second step presumes that several watermarks of a given type have been marked and the files saved to a common folder or library. The watermark to be tested is then compared to all the members of the library using the module watermarkLibrarySearch. The first two buttons shown in figure 43 are used to select the library of pre-marked watermarks and the unknown watermark, respectively. The third button activates the procedure, described in Appendix 3, to calculate the alignment error between the unknown watermark and all the watermarks in the library. Small alignment numbers mean that there is little error; the two watermark images are 
nearly identical. Large numbers mean that there is poor alignment between the labels of the watermarks. The output is a bar chart like those in seen in figures $25,29,32,35$, and 38 .

Once a likely match has been identified, an overlay video can be made directly in watermarkLibrarySearch or by using visualizeOverlays. The latter reads in two sets of files generated by watermarkPointMarker. Through the graphical user interface illustrated in figure 44 , the user selects a few options regarding the properties of the desired video and then presses the "Make Overlay" button. The overlay video provides the final opportunity to examine the two watermarks and to determine if they are, indeed, the same.

\section{Appendix 3}

70 Two watermark images, $I$ and $\bar{I}$, are annotated with $n$ corresponding points as shown in figures $3,5,8,12,14,3,19,21,22,24$, and 25 . An affine map from $I$ to $\bar{I}$ is parameterized by $\{A$, b $\}$, as in figure 45 , so that:

$$
\left(\begin{array}{l}
\bar{x}_{i} \\
\bar{y}_{i}
\end{array}\right)=\left(\begin{array}{ll}
a_{1,1} & a_{1,2} \\
a_{2,1} & a_{2,2}
\end{array}\right)\left(\begin{array}{l}
x_{i} \\
y_{i}
\end{array}\right)+\left(\begin{array}{l}
b_{1} \\
b_{2}
\end{array}\right)
$$

72 This is a system of $2 n$ equations in six unknowns. Rearranging so that the six unknown values occur in a vector, this becomes:

$$
\left(\begin{array}{cccccc}
x_{1} & y_{1} & 0 & 0 & 1 & 0 \\
0 & 0 & x_{1} & y_{1} & 0 & 1 \\
x_{2} & y_{2} & 0 & 0 & 1 & 0 \\
0 & 0 & x_{2} & y_{2} & 0 & 1 \\
x_{3} & y_{3} & 0 & 0 & 1 & 0 \\
0 & 0 & x_{3} & y_{3} & 0 & 1 \\
& \vdots & & & \vdots &
\end{array}\right)\left(\begin{array}{c}
a_{1,1} \\
a_{1,2} \\
a_{2,1} \\
a_{2,2} \\
b_{1} \\
b_{2}
\end{array}\right) \approx\left(\begin{array}{c}
\bar{x}_{1} \\
\bar{y}_{1} \\
\bar{x}_{2} \\
\bar{y}_{2} \\
\bar{x}_{3} \\
\bar{y}_{3} \\
\vdots
\end{array}\right) .
$$

74 Let $M$ be the large matrix, $\theta$ be the vector containing $a_{i, j}$ and $b_{i}$, and let $z$ be the vector containing the $\bar{x}_{i}$ and $\bar{y}_{i}$. By selecting the corresponding points on the watermarked images $I$ and $\bar{I}$, both $M$ and $z$ are known. The mapping $\theta$ that minimizes the error

$$
75\|M \theta-z\|_{2}
$$

76 defines the best affine map between the $x, y$ pairs and the $\bar{x}, \bar{y}$ pairs. The solution to the problem is called "Least Squares" and is well known to be:

$$
77 \quad \theta^{*}=\left(M^{T} M\right)^{-1} M^{T} Z .
$$

78 The total error between all the labeled points in $\bar{I}$ and their images under the mapping $\theta^{*}$ is: 


$$
79 r=\|M \theta-z\|_{2} \text {. }
$$

80 There are two subtleties that occur in this application. The first is that the total raw error will tend to increase as more points are measured. But the error between the two underlying images $I$ and $\bar{I}$ should be independent of the number of corresponding points selected. Accordingly, it is reasonable to calculate the error using the average misalignment of the labeled points (rather than the total misalignment), that is, to use $r / n$ in place of $r$ itself.

81 The second subtlety arises because of the symmetry between $I$ and $\bar{I}$. Thinking of the raw error $r$ in (5) as a kind of "distance" between the two watermark images, it is reasonable to expect that the distance from $I$ to $\bar{I}$ would be the same as the distance from $\bar{I}$ to $I$. As suggested by the curved arrows in figure 31, the best affine mapping from $\bar{I}$ to $I$ is given by the inverse of the mapping from $I$ to $\bar{I}$.These two errors will, in general, be unequal, because the $\{A, \mathrm{~b}\}$ mapping measures the error (in units of pixels) in the space of image $\bar{I}$ while the inverse $\left\{A^{-1},-A^{-1} \mathrm{~b}\right\}$ measures the error (in units of pixels) in the space of image $I$. A clear example is when $I$ and $\bar{I}$ have different resolutions; for example, one might be $600 \mathrm{dpi}$ while the other is $100 \mathrm{dpi}$. All else being equal, the calculated error in the higher-resolution image would be (six times) larger.

82 This could be resolved if the actual resolution of the images were known, but this information is often unavailable. Fortunately, it is possible to use the labeled points themselves to approximate the disparity in resolution. Figure 31 shows the bounding boxes of the labeled points in $I$ and $\bar{I}$ shaded in gray. The width of these boxes is $\beta_{1}$ and $\bar{\beta}_{1}$, and the heights are $\beta_{2}$ and $\bar{\beta}_{2}$. The ratios $\beta_{1} / \bar{\beta}_{1}$ and $\beta_{2} / \bar{\beta}_{2}$ thus provide an approximation of the ratio of the resolutions. For numerical reasons, we choose to measure the error using the average of the two ratios, and thus the error measure is:

$$
e=\frac{r}{n} \sqrt{\operatorname{avg}\left\{\frac{\beta_{1}}{\bar{\beta}_{1}}, \frac{\beta_{2}}{\bar{\beta}_{2}}\right\}}
$$

\section{Acknowledgements}

The authors wish to express their gratitude to Sound \& Vision Publishers for permission for the WIRE Project at Cornell University, of which C. Richard Johnson Jr. is a co-founder, to use their images of the watermarks appearing in Hinterding's catalogue as a critical part of the watermark identification procedure presented in this article, which we intend to add to the WIRE Project's website. The authors also thank the Metropolitan Museum of Art, the Morgan Library \& Museum, the Staatliche Graphische Sammlung München, the Dutch University Institute for Art History, and Theo and Frans Laurentius for access to images from their radiograph collections. The authors thank Nadine Orenstein (Metropolitan Museum of Art), Erik Hinterding (Rijksmuseum), and Andy Weislogel (Herbert F. Johnson Museum of Art, Cornell University) for their helpful comments on early versions of this article and Daniel Biddle (Stephen Chan Library, New York University) for his assistance. The authors thank the Getty Foundation 
Digital Art History Initiative Grant ORG-201943572, “Applying Digital Image Processing Algorithms to the Study of Prints and Drawings" (May 2019-September 2021), which has funded the development and application of computer-based tools that assist in the matching of manufactured patterns in laid paper. Gratitude is extended to the participants in the Foundation for Advancement in Conservation online workshop, "Coding Historical Papers: Identifying Sameness and Difference in Watermarks, Chain Lines, and Laid Lines" on March 1, 3, and 5, 2021 (https://www.iiconservation.org/content/coding-historical-papers-online-workshop), who served as first concept and software testers. Finally, the authors thank Associate Editor Bret Rothstein and Managing Editor Jennifer Henel, who provided invaluable assistance with the editing and layout of this article.

\section{Biographies}

C. Richard Johnson Jr. is the Geoffrey S. M. Hedrick Senior Professor of Engineering Emeritus at Cornell University in Ithaca, NY. Since 2007, his research has used digital signal processing to address issues in computational art history, primarily through the matching of manufactured patterns in art supports. Professor Johnson's contributions to canvas weave-mapping using Fourier analysis for rollmate identification, photographic paper classification via texture analysis, laid paper chain line pattern analysis for moldmate verification, and watermark identification using decision-tree construction for batchmate designation have appeared in numerous publications. (http://countingvermeer.rkdmonographs.nl).

crj2@cornell.edu

William A. Sethares is a professor in the Department of Electrical and Computer Engineering at the University of Wisconsin in Madison. He is a scientific researcher at the Rijksmuseum in Amsterdam and is the Honorary International Chair Professor at the National Taipei University of Technology. He is interested in image and audio processing with special focus on the imaging and the interpretation of historical papers and canvases.

sethares@wisc.edu

Margaret Holben Ellis is the Eugene Thaw Professor Emerita of Paper Conservation at the Institute of Fine Arts, New York University, where she teaches the conservation treatment of prints and drawings and technical connoisseurship for art historians. She has published and lectured on artists ranging from Raphael, Dürer, and Titian to Pollock, Samaras, Lichtenstein, and Dubuffet. Her research on artists' materials and techniques is also broad, encompassing Day-Glo colors, Magic Markers, and Crayola crayons, and, most recently, pre-machine-made European papers.

mhe1@nyu.edu 


\section{Illustrations}

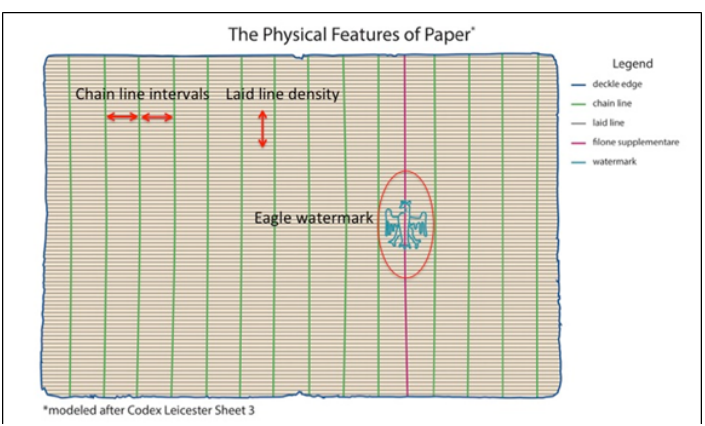

Fig. 1 The manufactured patterns found in paper reflect the unique characteristics of the papermaking mold used to form it. Papers made from the same mold — moldmates — share subtle variations in watermark details, chain line intervals, and laid line densities measured in lines per centimeter. The filone supplementare, or supplemental wire, is characteristic of fifteenth- and sixteenthcentury papers produced in the vicinity of Fabriano. See S. R. Albro, Fabriano: City of Medieval and Renaissance Papermaking (New Castle, DE: Oak Knoll Press, 2016), 147. Drawing by A. Slawik

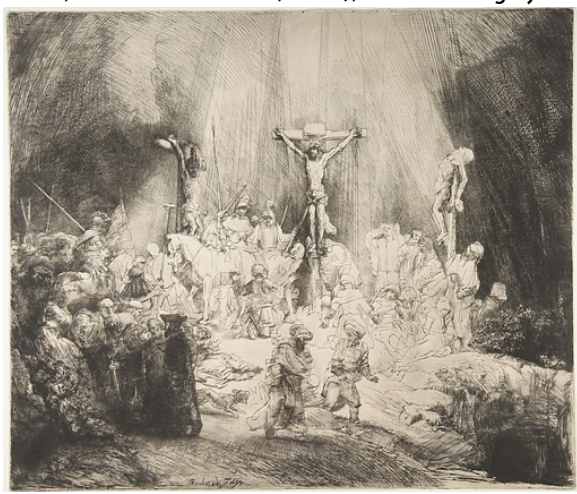

Fig. 2 Rembrandt van Rijn, Christ Crucified Between Two Thieves (The Three (rosses), 1653, state B78iii, The Metropolitan Museum of Art, New York, 41.1.32

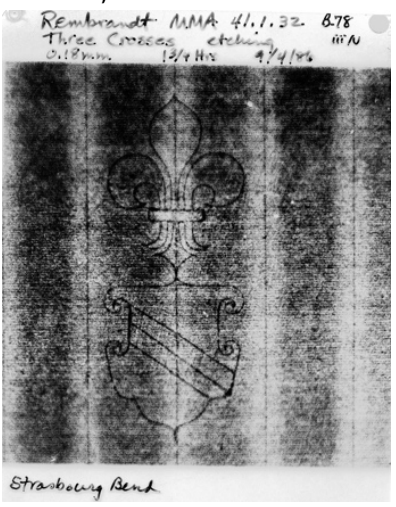

Fig. 3 Radiograph of watermark, Rembrandt, Christ Crucified, B78iii (fig. 2), Radiograph by R. Snyder

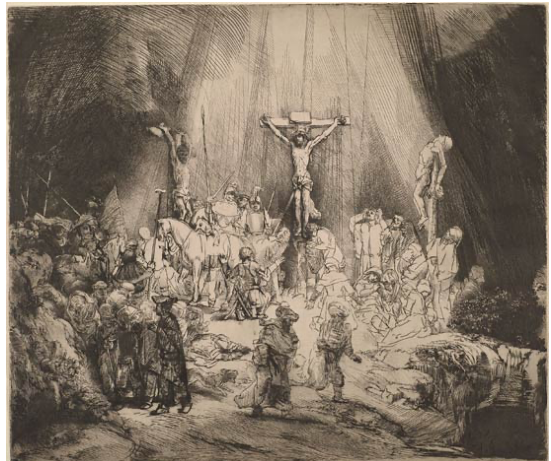

Fig. 4 Rembrandt van Rijn, Christ Crucified Between Two Thieves (The Three (rosses), 1653, state B78ii, The Morgan Library and Museum, New York, RvR 122

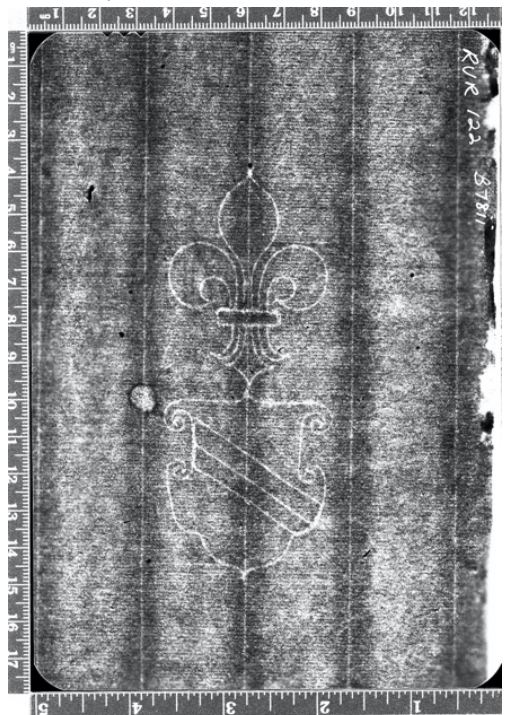

Fig. 5 Radiograph of watermark, Rembrandt, Christ Crucified, B78ii (fig. 4), Radiograph by R. Snyder

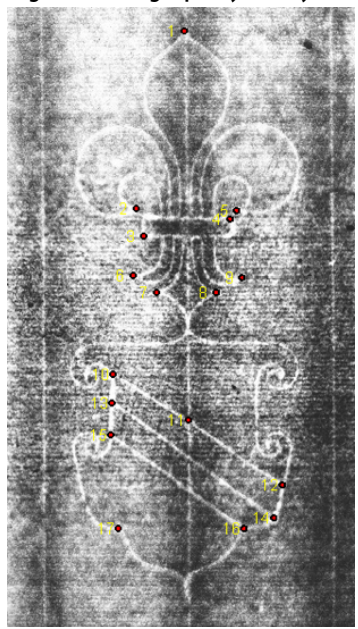

Fig. 6 Marked Strasbourg Bend watermark, Rembrandt, Christ Crucified, B78iii (fig. 3) 


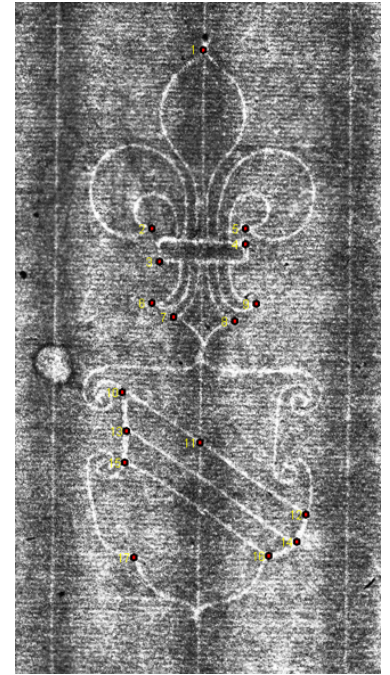

Fig. 7 Marked Strasbourg Bend watermark, Rembrandt, Christ Crucified, B78ii (fig. 5)

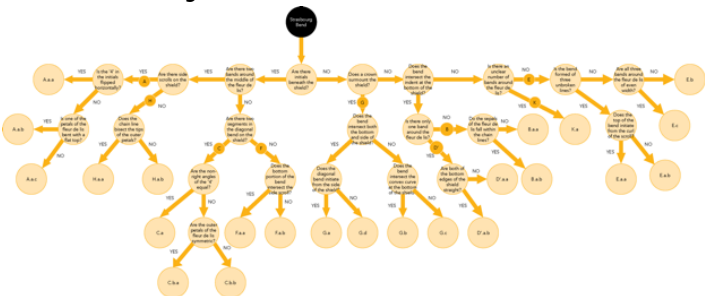

Fig. 8 Strasbourg Bend decision tree from WIRE Project at Cornell

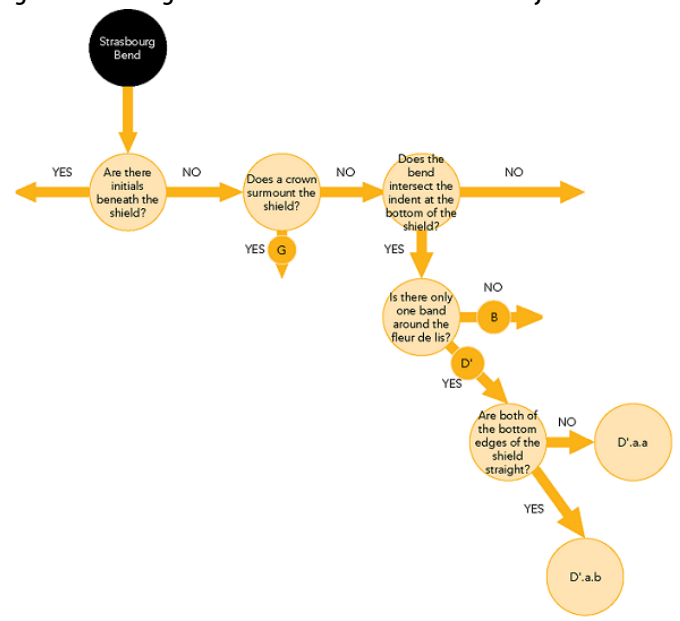

Fig. 9 Strasbourg Bend decision tree path to $D^{\prime}$.a.a and D'.a.b

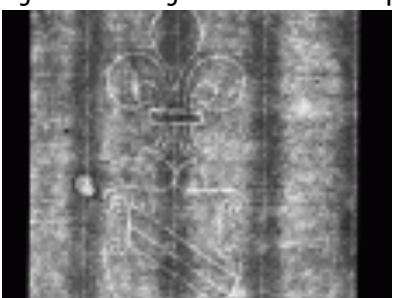

Fig. 10 Overlay GIF of marked Strasbourg Bend watermarks (figs. 6 and 7).

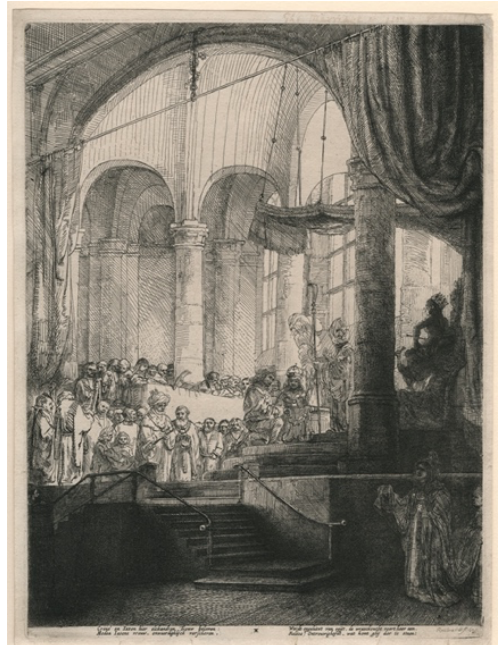

Fig. 11 Rembrandt van Rijn, Medea, or the Marriage of Jason and Creusa, 1648, B112iv, The Morgan Library \& Museum, New York, RvR 178

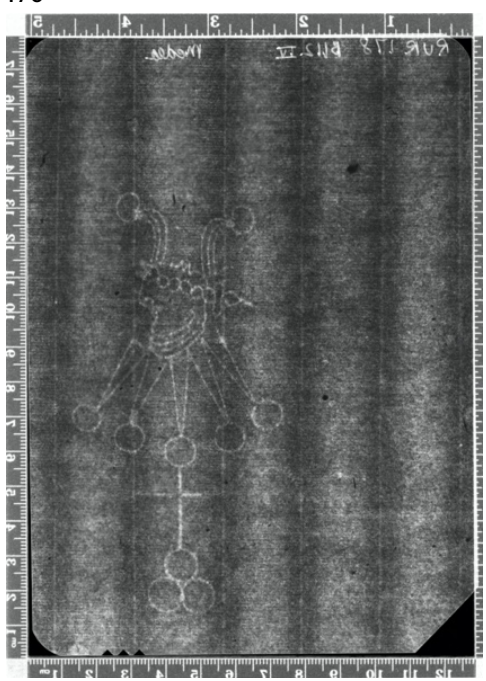

Fig. 12 Radiograph of watermark, Rembrandt, Medea, B112iv (fig. 11) Radiograph by R. Snyder

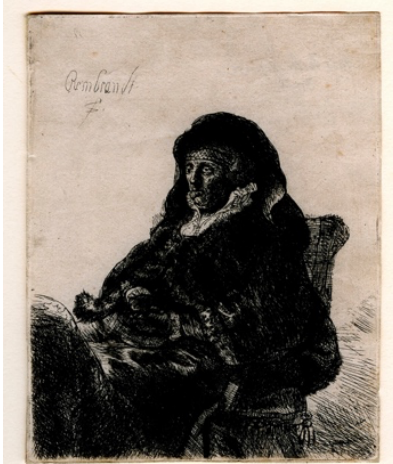

Fig. 13 Rembrandt van Rijn, The Artist's Mother in Widow's Dress and Black Gloves, ca. 1635, B344, The Morgan Library \& Museum, RvR 459 


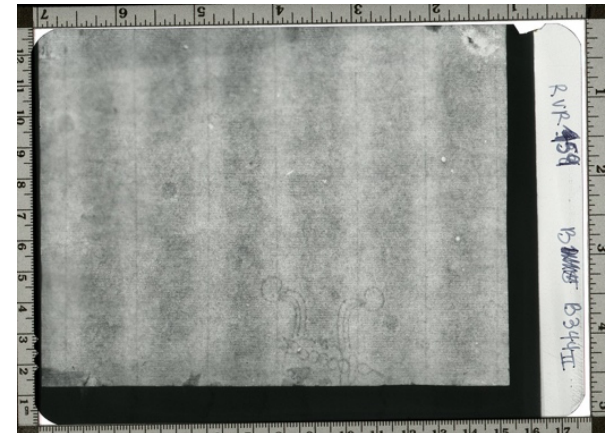

Fig. 14 Radiograph of watermark, Rembrandt, The Artist's Mother, B344 (fig. 13), Radiograph by R. Snyder

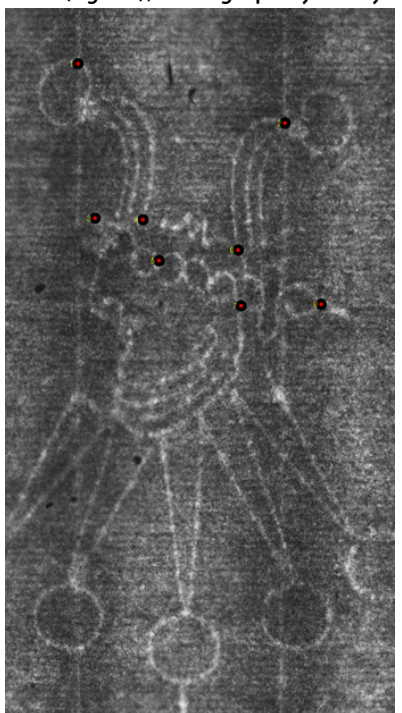

Fig. 15 Marked Foolscap with Five-Pointed Collar watermark, B112iv (fig. 12)

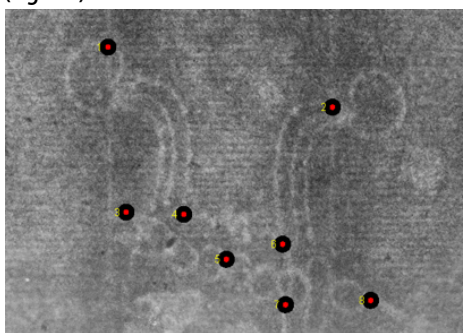

Fig. 16 Marked Foolscap with Five-Pointed Collar watermark B344 (fig. 14)

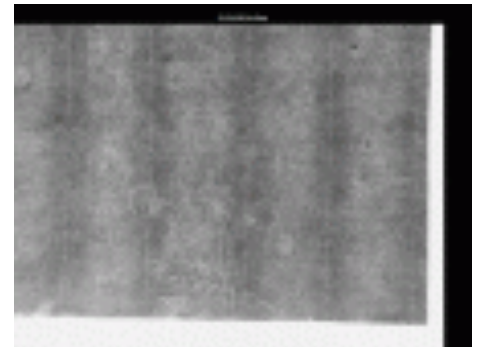

Fig. 17 Overlay GIF of marked Foolscap with Five-Pointed Collar watermarks (figs. 15 and 16).

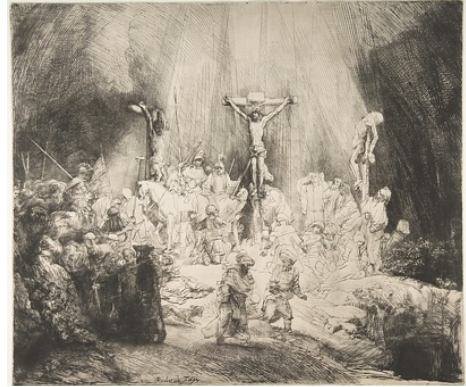

Fig. 2a Rembrandt, Christ Crucified, state B78iii (fig. 2)

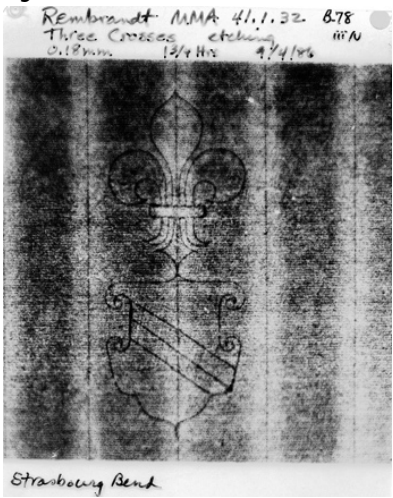

Fig. 3a Radiograph of watermark, Rembrandt, Christ Crucified, state B78iii (fig. 3)

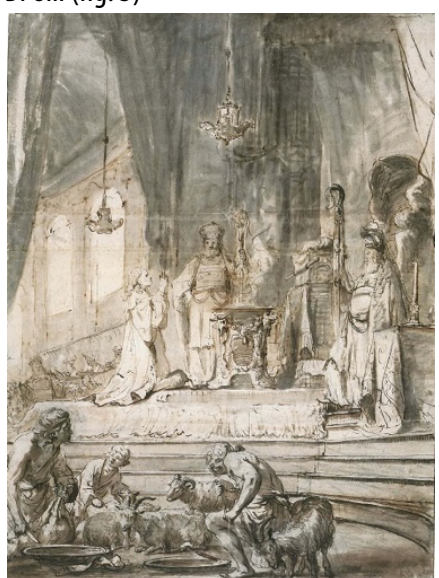

Fig. 18 Ferdinand Bol, Solomon Offering a Sacrifice of Peace Offerings (image from T. Vignau-Wilberg, Rembrandt auf Papier: Werk und Wirkung [Hirmer: Munich, 2001] @Staatliche Graphische Sammlung München)

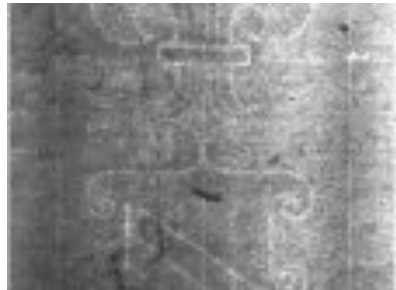

Fig. 19 Radiograph of watermark, Bol, Solomon Offering a Sacrifice (image from T. Vignau-Wilberg, Rembrandt auf Papier: Werk und Wirkung [Hirmer: Munich, 2001] @Staatliche Graphische Sammlung München) 


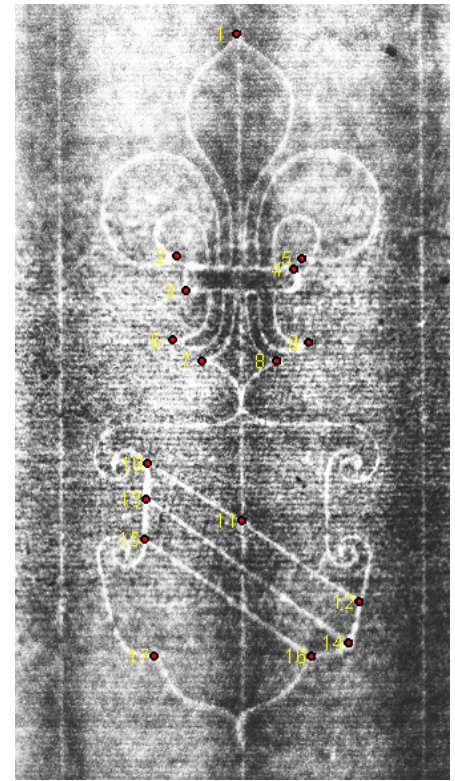

Fig. 6a Marked Strasbourg Bend watermark, Rembrandt, Christ Crucified, B78iii (fig. 6)

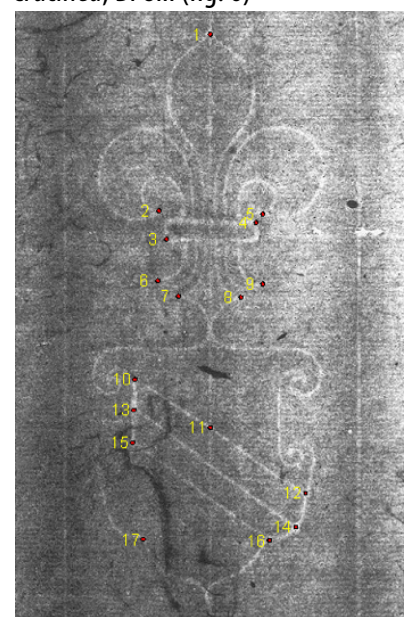

Fig. 19a Marked Strasbourg Bend watermark, Bol, Solomon Offering a Sacrifice (fig. 19)

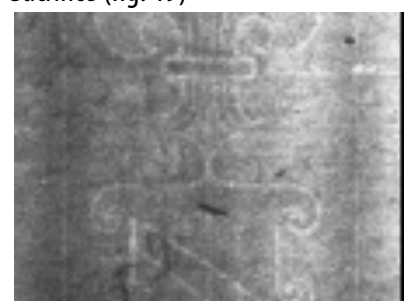

Fig. 20 Overlay GIF of marked Strasbourg Bend watermarks (figs. 6 and 19)

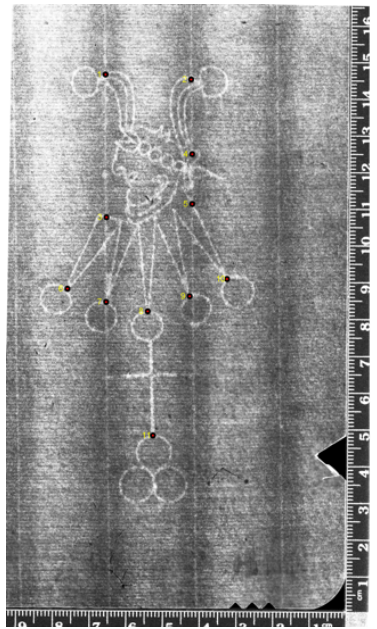

Fig. 24a Marked beta radiograph of watermark, Rembrandt, The Bridge at Klein Kostverloren, B208ii (fig. 24)

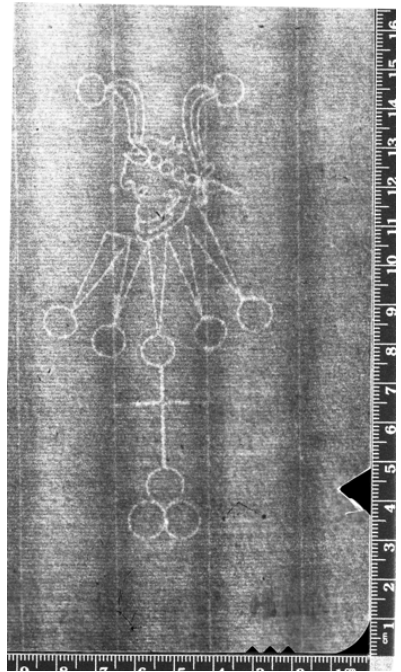

Fig. 26 Watermark in Rembrandt van Rijn, The Bridge at Klein Kostverloren, 1645, B208ii

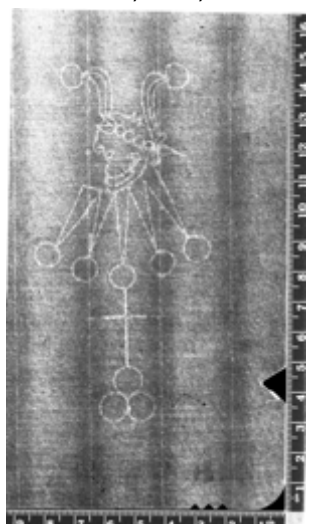

Fig. 26a Watermark in Rembrandt, The Bridge at Klein Kostverloren, B208ii (fig. 26) 


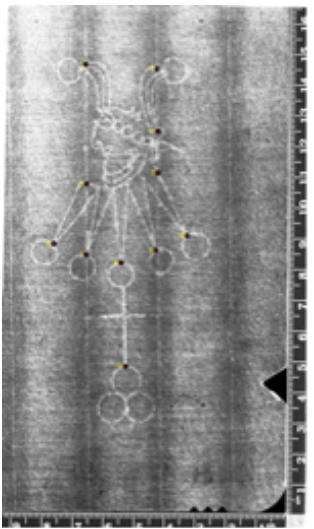

Fig. 24b Marked beta radiograph of watermark, Rembrandt, The Bridge at Klein Kostverloren, B208ii (fig. 24)

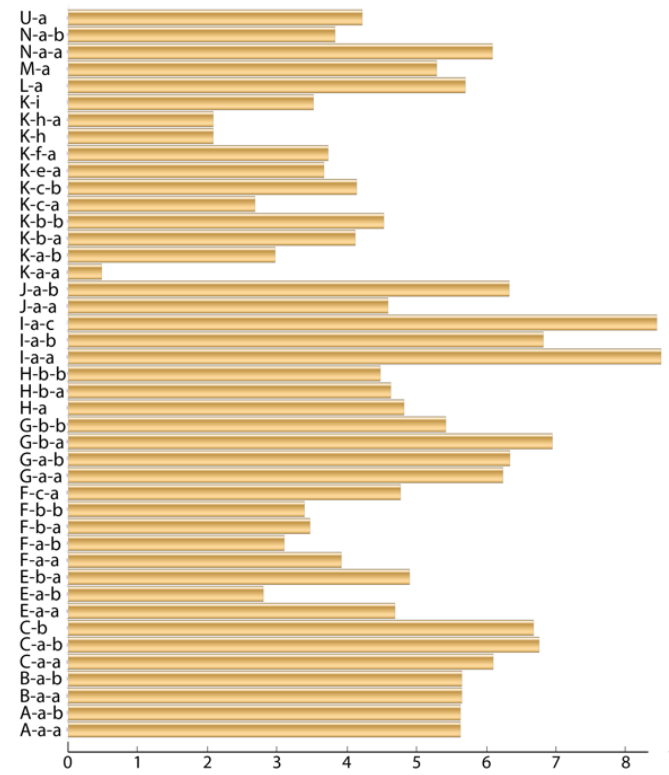

Fig. 25a Average alignment errors for Morgan RVR 294 (fig. 25)

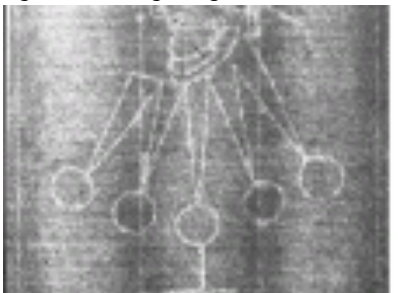

Fig. 27 Overlay GIF of radiograph watermark (marked and unmarked) in figs. 24 and 26

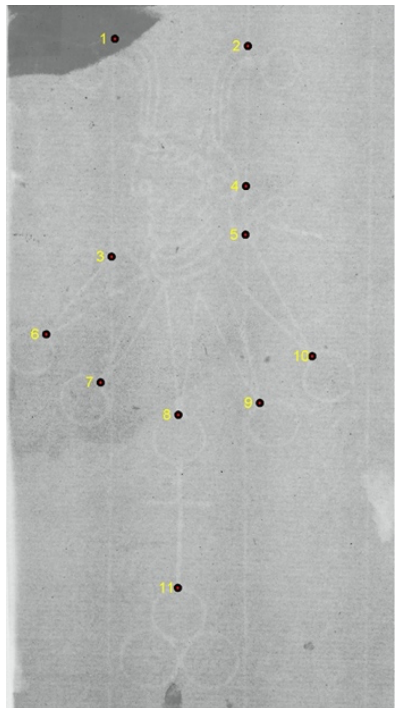

Fig. 28 Marked radiograph EH002026 of watermark in Jan Gillisz van Vliet, Old Woman Reading, B18ii, from the watermark collection of the Dutch University Institute for Art History in Florence. Publication permission granted by Gert Jan van der Sman, NIKI (Marking by C. Richard Johnson Jr.)

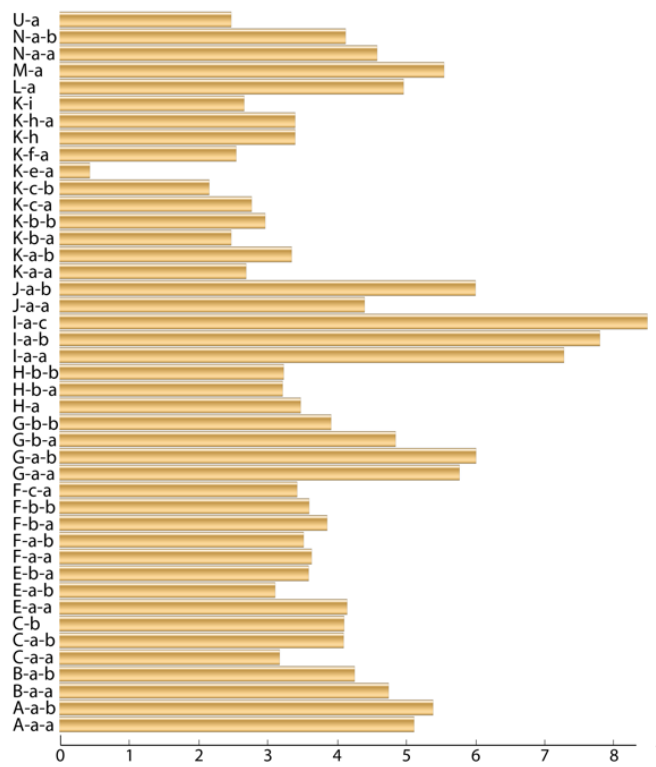

Fig. 29 Average alignment errors for NIKI EH002026 (fig. 28) in comparison to marked images of Foolscaps with Five-Pointed Collar watermarks in Appendix 1

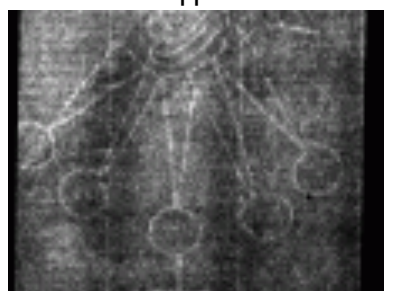

Fig. 30 Overlay GIF of marked radiograph, Van Vliet, Old Woman Reading, B18ii (fig. 28 


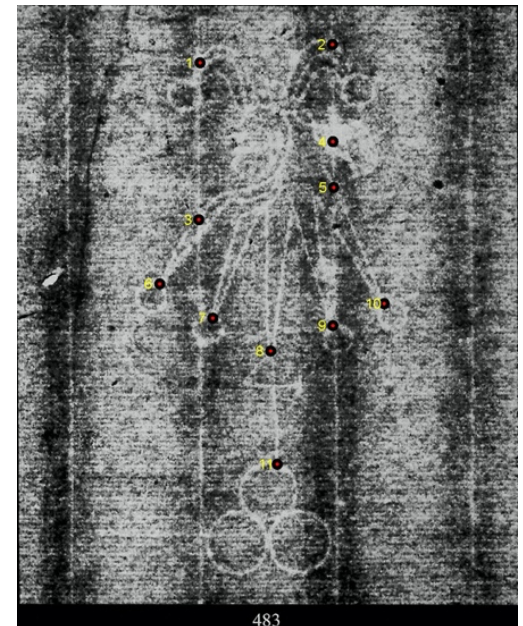

Fig. 31 Marked Foolscap with Five-Pointed Collar watermark number 483 from Theo and Frans Laurentius, Watermarks 1600-1650: Found in the Zeeland Archives ('t Goy-Houten: Hes \& De Graaf, 2007),

Publication permission granted by Frans Laurentius (Marking by $C$. Richard Johnson Jr.)

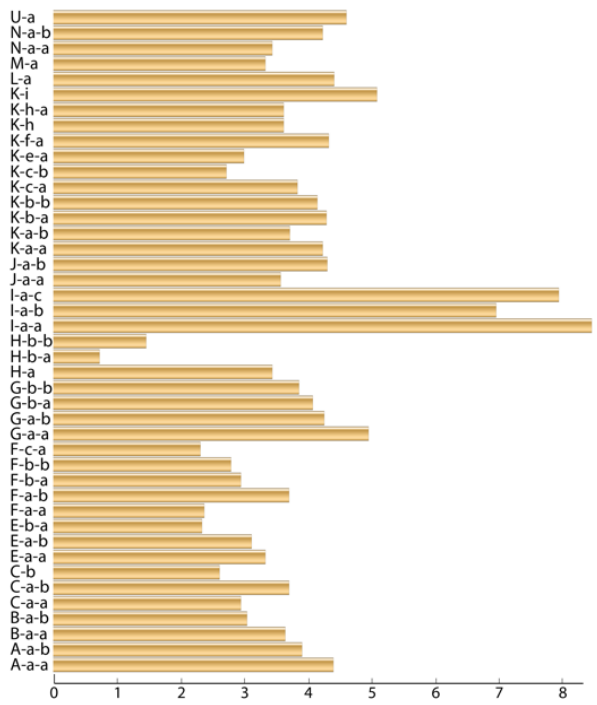

Fig. 32 Average alignment errors for Laurentius 483 in comparison to marked images of Foolscaps with Five-Pointed Collar Watermarks in Appendix 1

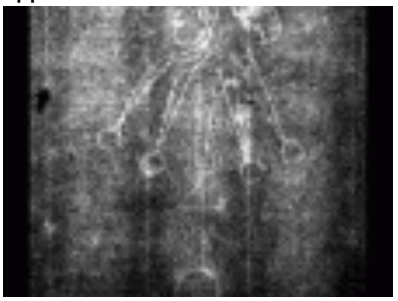

Fig. 33 Overlay GIF of marked Foolscap with Five-Pointed Collar watermark (fig. 31).

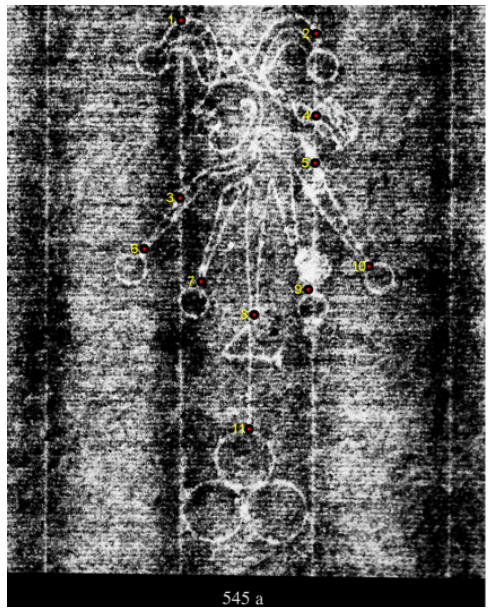

Fig. 34 Marked Foolscap with Five-Pointed Collar watermark number 545a from Laurentius, Watermarks 1600-1650 (Marking by C. Richard Johnson Jr.)

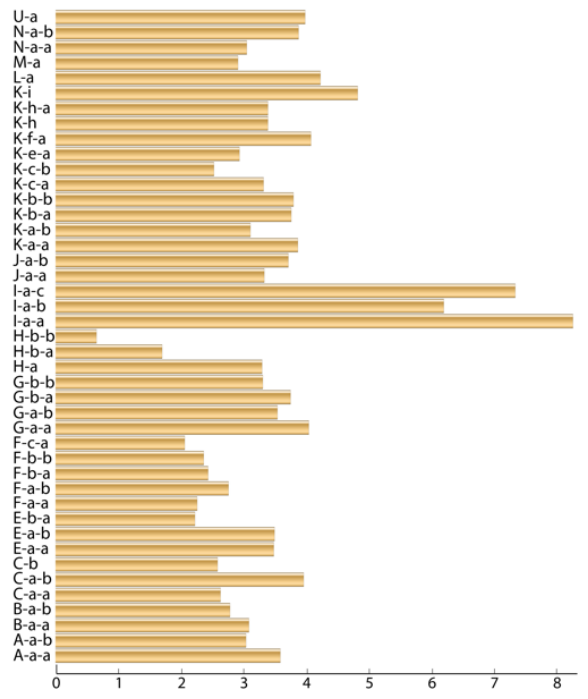

Fig. 35 Average alignment errors for Laurentius 545a in comparison to marked images of Foolscaps with Five-Pointed Collar watermarks in Appendix 1

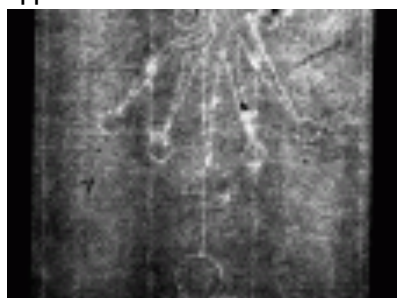

Fig. 36 Overlay GIF of marked Foolscap with Five-Pointed Collar watermark (fig. 34) 


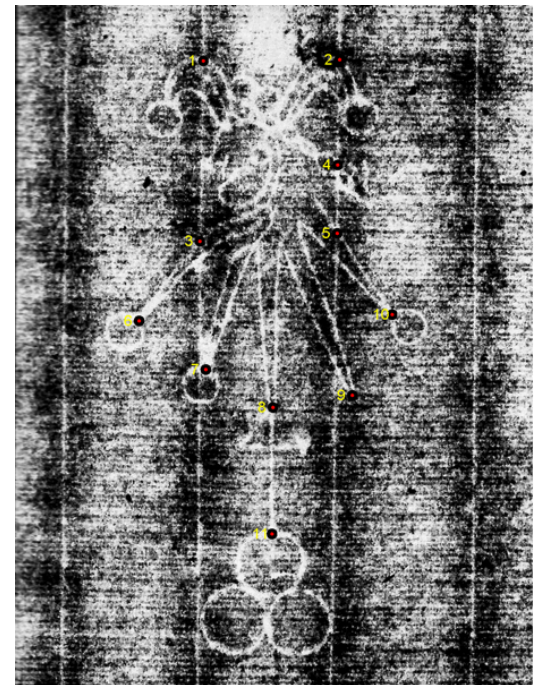

Fig. 37 Marked Foolscap with Five-Pointed Collar watermark number 544a from Laurentius, Watermarks 1600-1650. Marking by C. Richard Johnson Jr.

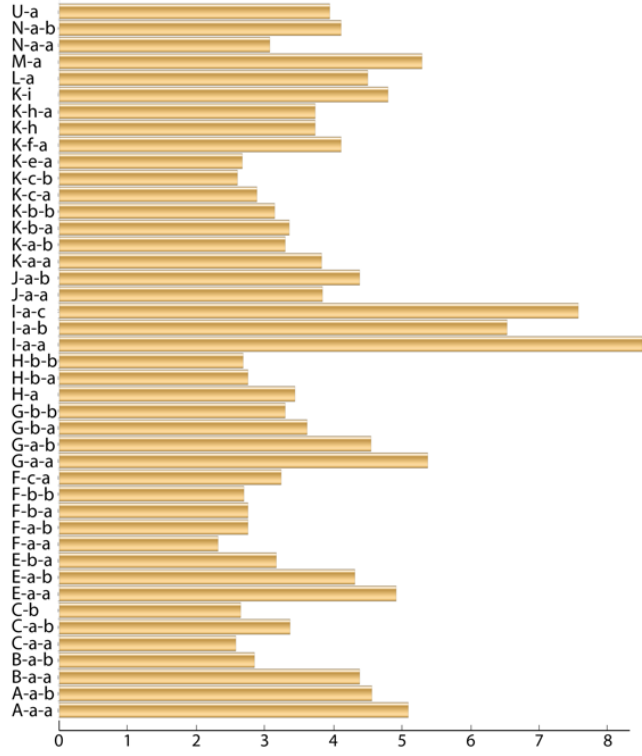

Fig. 38 Average alignment errors for Laurentius 544a in comparison to marked images of Foolscaps with Five-Pointed Collar watermarks in Appendix 1

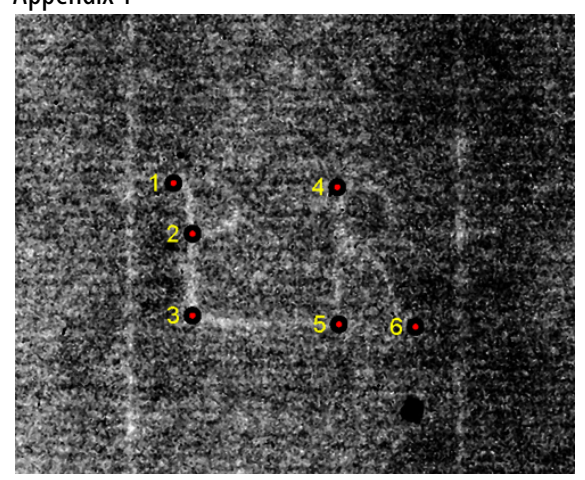

Fig. 39 Marked PR countermark, PR.a from Erik Hinterding, Rembrandt as an Etcher (Ouderkerk aan den IJssel: Sound \& Vision, 2006).

Publication permission granted by Sound \& Vision Publishers BV

(Marking by C. Richard Johnson Jr.)

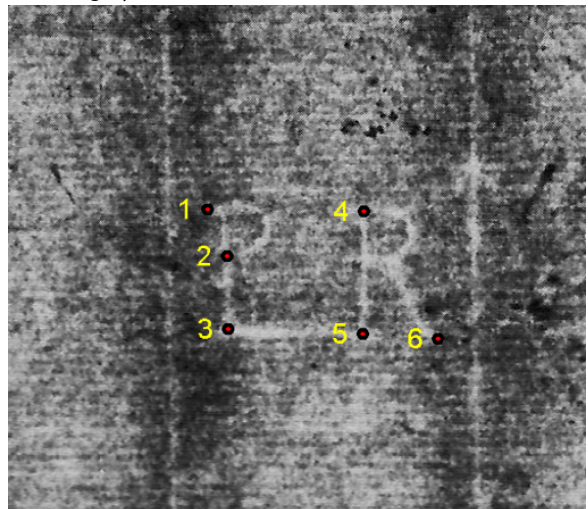

Fig. 40 Marked PR countermark, watermark 545b from

Laurentius, Watermarks 1600-1650. (Marking by C. Richard Johnson Jr.)

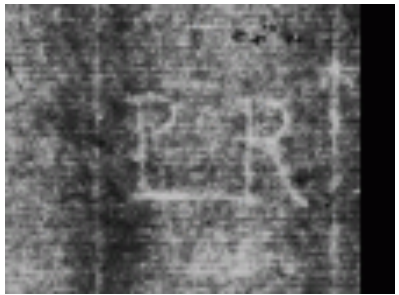

Fig. 41 Overlay GIF of marked PR countermarks (figs. 39 and 40).

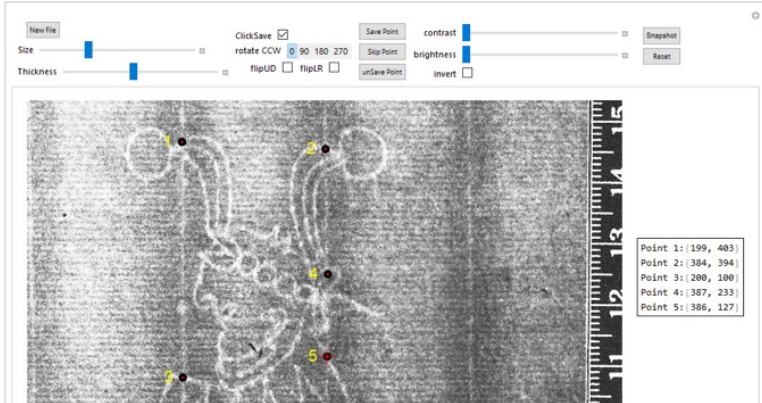

Fig. 42 The graphical user interface for the selection of the corresponding points between images (with the first five of the eleven to be marked in the Foolscap with Five-Pointed Collar)

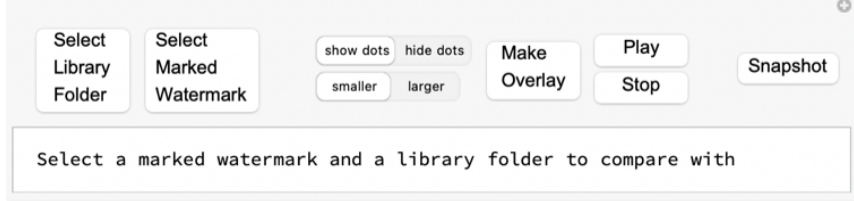

Fig. 43 The graphical user interface for watermarkLibrarySearch. After the user selects a folder containing pre-marked watermark images and a single (usually unknown) watermark, the module calculates the alignment error between the unknown and each of the members of the library, as described in Appendix 3. 


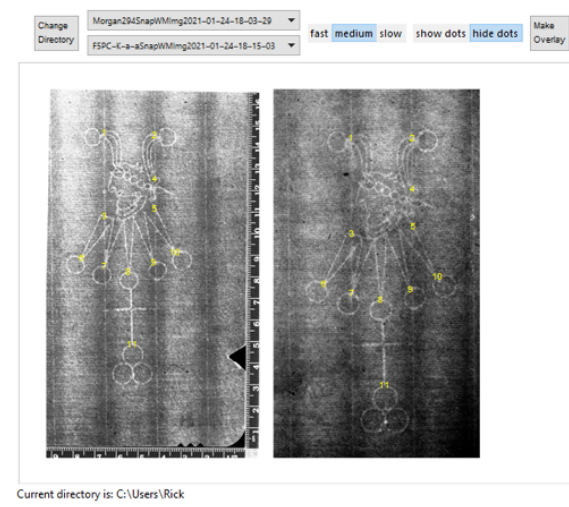

Fig. 44 The graphical user interface for the generation of overlay animations uses the output of watermarkPointMarker to guide the creation of the animation. Careful observation of the video is the final step in determining the moldmate status of the watermark images.

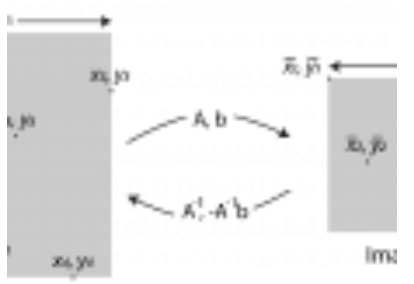

Fig. 45 Sets of points marking the left-hand figure are labeled with $x$ and $y$ (and subscripted by $i$ ), while the corresponding points on the right are labeled with the overbars (The case $i=5$ is shown). The affine mapping from left to right is given by the matrix $A$ and vector $b$. The bounding box of each set of labels is used to scale the error so that the comparison becomes independent of the resolution of the watermarked images.

\section{Bibliography}

Abry, Patrice, Andrew G. Klein, Paul Messier, Stéphane Roux, Margaret Holben Ellis, William A. Sethares, David Picard, Yuanhao Zhai, David L. Neuhoff, Herwig Wendt, Stéphane Jaffard, and C. Richard Johnson Jr. "Wove Paper Analysis through Texture Similarities." In Proceedings of the 50th IEEE Annual Asilomar Conference on Signals, Systems, and Computers (ASILOMAR 2016), 144-48. Pacific Grove, CA: IEEE, 2016.

Ash, Nancy, and Shelley Fletcher. Watermarks in Rembrandt's Prints. Washington: National Gallery of Art, 1998.

The Bernstein Consortium, Commission for Scientific Visualization (VISKOM), Austrian Academy of Sciences. “The Memory of Paper” (website). Last modified January 15, 2021. https://www.memoryofpaper.eu/BernsteinPortal.

Bounou, Oumayma, Tom Monnier, Ilaria Pastrolin, Xi Shen, Christine Benevent, MariaFrançoise Limon-Bonnet, François Bougard, Mathieu Aubry, Marc H. Smith, and Oliver Poncet, et al. “A Web Application for Watermark Recognition.” Journal of Data Mining and Digital Humanities 24, no. 45 (July 17, 2020): https://jdmdh.episciences.org/6570.

Van Camp, An. "Rembrandt's Early Works on Paper." In Young Rembrandt, ed. An Van Camp, Christopher Brown, and Christiaan Vogelaar, 57-77. Oxford: Ashmolean Museum, University of Oxford, 2020.

Centre for the Study of the Renaissance, Warwick University. "Lima: Watermark Databases." Last modified February 4, 2021. https://warwick.ac.uk/fac/arts/ren/archive-researchold/lima/paper/describing/databases. 
Doynov, Plamen."Framework for Automatic Identification of Paper Watermarks with Chain Codes. PhD diss., University of Missouri-Kansas City, 2017.

Dutch University Institute for Art History. "Watermarks," accessed March 9, 2021, https://www.niki-florence.org/en/about-the-institute/research/\%20projects/watermarks.

Ellis, Margaret Holben, and C. Richard Johnson Jr. "Computational Connoisseurship: Enhanced Examination Using Automated Image Analysis.” Visual Resources 35, nos. 1-2, (2019): 125-40.

Gorske, Sara F., C. Richard Johnson Jr., William A. Sethares, Margaret Holben Ellis and Paul Messier. "Moldmate Identification in 16th-Century European Paper Using Quantitative Analysis of Watermarks, Chain Line Intervals, and Laid Line Density." International Journal for Digital Art History 5 (March 3, 2021): https://doi.org/10.11588/dah.2020.5.71232.

Hinterding, Erik. "Rembrandt and Van Vliet: The Watermarks." In Rembrandt and Van Vliet: A Collaboration on Copper, edited by Christian Schuckman, Michael Royalton-Kisch, and Erik Hinterding, 24-37. Amsterdam: Museum het Rembrandthuis, 1996.

-. Rembrandt as an Etcher. Ouderkerk aan den IJssel: Sound \& Vision, 2006. International Association of Paper Historians. "Printed Watermark Repertories." Last updated February 22, 2021. http://www.paperhistory.org/Watermark-catalogues.

International Standard for the Registration of Papers with or without Watermarks, version 2.1.1, 2013. http://www.paperhistory.org/Standards/IPHN2.1.1 en.pdf.

Johnson Jr., C. Richard. “Decision Trees for Watermark Identification in Rembrandt's Etchings." Journal of Historians of Netherlandish Art 12, no. 2 (Summer 2020), https://jhna.org/articles/decision-trees-for-watermark-identification-in-rembrandts-etchings.

- "The Watermark Identification in Rembrandt's Etchings (WIRE) Project at Cornell," recorded December 6, 2018 at The Frick Collection, New York, 1:50:05, https://www.frick.org/interact/wire project cornell.

Johnson, Don H., C. Richard Johnson Jr., and Robert G. Erdmann. "Weave Analysis of Paintings on Canvas from Radiographs.” Signal Processing 93, no. 3 (March 2013): 527-40.

Johnson Jr., C. Richard, Paul Messier, William A. Sethares, Andrew Klein, Christopher Brown, Anh Hoang Do, Philip Klausmeyer, Patrice Abry, Stephané Jaffard, Herwig Wendt, Stephané Roux, Nelly Pustelnik, Nanne van Noord, Laurens van der Matten, Eric Postma, James Coddington, Lee Ann Daffner, Hanako Murata, Henry Wilhelm, Sally Wood, and Mark Messier. "Pursuing Automated Classification of Historic Photographic Papers from Raking Light Images." Journal of the American Institute for Conservation 53, no. 3 (2014): 159-70. 
Johnson Jr., C. Richard, and William A. Sethares, eds. Counting Vermeer: Using Weave Maps to Study Vermeer's Canvases. The Hague: RKD Studies, 2017.

https://countingvermeer.rkdstudies.nl.

—. "Hunting for Weave Matches: Computation in Art Scholarship." Journal of Interactive

Technology and Pedagogy 12 (February 2018), https://jitp.commons.gc.cuny.edu/HUNTINGFOR-WEAVE-MATCHES-COMPUTATION-IN-ART-SCHOLARSHIP/.

Johnson Jr., C. Richard, William A. Sethares, Margaret Holben Ellis, and Saira Haqqi. "Hunting for Paper Moldmates Among Rembrandt's Prints." IEEE Signal Processing Magazine 32, no. 4 (July 2015): 28-37.

Johnson Jr, C. Richard, William A. Sethares, Margaret Holben Ellis, Saira Haqqi, Reba Snyder, Erik Hinterding, Idelette van Leeuwen, Arie Wallert, Dionysia Christoforou et al.. "The Application of Automated Chain Line Pattern (CLiP) Matching to Identify Paper Mouldmate Candidates in Rembrandt's Prints." In Rembrandt and His Circle: Insights and Discoveries, ed. Stephanie Dickey, 319-34. Amsterdam: University of Amsterdam Press, 2017

Laurentius, Theo, and Frans Laurentius. Watermarks 1600-1650: Found in the Zeeland Archives. 't Goy-Houten: Hes \& De Graaf, 2007.

Liedtke, Walter, C. Richard Johnson Jr., and Don H. Johnson. "Canvas Matches in Vermeer: A Case Study in the Computer Analysis of Fabric Supports." Metropolitan Museum Journal 47 (2012): 99-106.

Lister, Kristin Hoermann, Cornelia Peres, and Inge Fiedler. "Tracing an Interaction: Supporting Evidence, Experimental Grounds.” In Van Gogh and Gauguin: The Studio of the South, edited by Douglas W. Druick and Peter Kort Zegers, 354-69. London: Thames and Hudson, 2001.

Van der Lubbe, Jan C. A., Eugene P. van Someren, and Marcel J. T. Reinders. "Dating and Authentication of Rembrandt's Etchings with the Help of Computational Intelligence." In International Cultural Heritage Informatics: Proceedings from ichim0, 485-92. Milan and Pittsburgh: Archives and Museum Informatics, 2001.

Van der Maaten, Laurens, and Robert G. Erdmann. "Automatic Thread-Level Canvas Analysis: A Machine-Learning Approach to Analyzing the Canvas of Paintings.” IEEE Signal Processing Magazine 32, no. 4 (July 2015): 38-45.

Messier, Paul, C. Richard Johnson Jr., Henry Wilhelm, William A. Sethares, Andrew G. Klein, Patrice Abry, Stephané Jaffard, Herwig Wendt, Stephane Roux, Nelly Pustelnik, Nanne van Noord, Laurens van der Matten, and Eric Postma."Automated Surface Texture Classification of Inkjet and Photographic Media." In Technical Program and Proceedings: NIP29: The 29th International Conference on Digital Printing Technologies, 85-91. Springfield, VA: The Society for Imaging Science and Technologies, 2013. 
Messier, Paul. “Image Isn't Everything: Revealing Affinities Across Collections Through the Language of the Photographic Print." In Object: Photo. Modern Photographs: The Thomas Walther Collection 1909-1949, edited by Mitra Abbaspour, Lee Ann Daffner, and Maria Morris Hambourg, 1-11. New York: Museum of Modern Art, 2014.

Vander Meulen, David. "The Identification of Paper without Watermarks: The Example of Pope's 'Dunciad.”' Studies in Bibliography 37 (1984): 58-81.

Pardo, Lucia P., and Giles Bergel, "Watermarks: New Ways to See and Search Them” (blog post), July 30, 2020. National Archives, London. https://blog.nationalarchives.gov.uk/watermarks-new-ways-to-see-and-search-them.

Perez d'Ors, Pablo, C. Richard Johnson Jr., and Don H. Johnson. "Velázquez in Fraga: A New Hypothesis about the Portraits of El Primo and Philip IV." Burlington Magazine 154, no. 1314 (September 2012): 620-25.

Picard, David, Thomas Henn, and Georg Dietz. "Non-Negative Dictionary Learning for Paper Watermark Similarity." In Proceedings of the 50th IEEE Asilomar Conference on Signals, Systems, and Computers (ASILOMAR 2016), 133-36. Pacific Grove, CA: IEEE, 2016.

Pondenkandath, Vinaychandran, Michele Alberti, Nicole Eichenberger, Rolf Ingold, and Marcus Liwicki. "Cross-Depicted Historical Motif Categorization and Retrieval with Deep Learning." Journal of Imaging 6(7), no. 71 (July 15, 2020): https://doi.org/10.3390/jimaging6070071.

Roberts, Jane. A Dictionary of Michelangelo's Watermarks. Milan: Olivetti, 1988.

Ruiz, Pablo, Olivia Dill, Goutam Raju, Oliver Cossairt, Marc Walton, Aggelos K. Katsaggelos. "Visible Transmission Imaging of Watermarks by Suppression of Occluding Text or Drawings." Digital Applications in Archaeology and Cultural Heritage 15 (December 2019): https://doi.org/10.1016/j.daach.2019.e00121.

Sethares, William A., Margaret Holben Ellis, and C. Richard Johnson Jr. "Computational Watermark Enhancement in Leonardo's Codex Leicester." Journal of the American Institute for Conservation 59, no. 2 (March 2020): 87-96.

Van Sloten, Leonore. "Ferdinand Bol, the Etcher." In Ferdinand Bol and Govert Flinck: Rembrandt's Master Pupils, ed. N. Middelkoop, 219-20. Zwolle: WBooks, 2017.

Van Staalduinen, Mark. "Content-Based Paper Retrieval Towards Reconstruction of Art History.” PhD diss., Delft University of Technology, 2010.

Stevenson, Allan H. "Chain-Indentations in Paper as Evidence." Studies in Bibliography 6, (1954): 181-95. 
-. "Watermarks are Twins." Studies in Bibliography 4 (1951-52): 57-91.

Van Tilborgh, Louis, Teio Meedendorp, Ella Hendriks, Don H. Johnson, C. Richard Johnson Jr., and Robert G. Erdmann. "Weave Matching and Dating Van Gogh's Paintings: An Interdisciplinary Approach.” Burlington Magazine 154, no. 1307 (2012): 112-22.

Vignau-Wilberg, Thea. Rembrandt auf Papier: Werk und Wirkung. Munich: Hirmer, 2001. Weislogel, Andrew C., and C. Richard Johnson Jr. "Decision Trees and Fruitful Collaborations: The Watermark Identification in Rembrandt's Etchings (WIRE) Project at Cornell." In Lines of Inquiry: Learning from Rembrandt's Etchings, edited by Andrew Weislogel and Andaleeb Banta, 32-57. Ithaca, NY: Herbert F. Johnson Museum of Art, Cornell University, 2017. http://museum.cornell.edu/sites/default/files/DecisionTrees-WeislogelJohnson2017LinesofInquiry.pdf.

Van der Wetering, Ernst. “The Canvas Support." In Rembrandt: The Painter at Work, 90-130. Berkeley: University of California Press, 2000.

Xi, Xuelie, Devin Conathan, Amanda House, William A. Sethares, and C. Richard Johnson, Jr. "Automated Chain Line Marking and Pattern Matching in Radiographs of Rembrandt's Prints." In Proceedings of the 50th IEEE Annual Asilomar Conference on Signals, Systems, and Computers (ASILOMAR 2016), 1-9. Pacific Grove, CA: IEEE, 2016.

Yang, Haizhao, Jianfeng Lu, William Brown, and Ingrid Daubechies. "Quantitative Canvas Weave Analysis Using 2-D Synchrosqueezed Transforms: Application of Time-Frequency Analysis to Art Investigation." IEEE Signal Processing Magazine 32, no. 4 (July 2015): 55-63.

\section{Endnotes}

1. "Comparability" refers to the equivalency of visibility, completeness, scale, orientation, resolution, degree of sameness, and overall quality between existing watermark images. Manually comparing watermark images having vastly different degrees of comparability is extremely difficult and leads to inaccurate conclusions.

2. Margaret Holben Ellis and C. Richard Johnson Jr., "Computational Connoisseurship: Enhanced Examination Using Automated Image Analysis," Visual Resources 35, nos. 1-2 (March-June 2019), 125-40.

3. Ernst van de Wetering, "The Canvas Support," in Rembrandt: The Painter at Work (Berkeley: University of California Press, 2000), 90-130.

4. Kristin Hoermann Lister, Cornelia Peres, and Inge Fiedler, "Tracing an Interaction: Supporting Evidence, Experimental Grounds" in Van Gogh and Gauguin: The Studio of the South, ed. Douglas W. Druick and Peter Kort Zegers (London: Thames and Hudson, 2001), 354-69. 
5. Don H. Johnson, C. Richard Johnson Jr., and Robert G. Erdmann, "Weave Analysis of Paintings on Canvas from Radiographs," Signal Processing 93, no. 3 (March 2013), 527-40.

6. Louis van Tilborgh et al., "Weave Matching and Dating of Van Gogh's Paintings: An Interdisciplinary Approach," Burlington Magazine 154, no. 1307 (February 2012), 112-22.

7. For example, Pablo Perez d'Ors, C. Richard Johnson Jr., and Don H. Johnson, "Velázquez in Fraga: A New Hypothesis about the Portraits of El Primo and Philip IV," Burlington Magazine 154, no. 1314 (September 2012), 620-25; and Walter Liedtke, C. Richard Johnson Jr., and Don H. Johnson, "Canvas Matches in Vermeer: A Case Study in the Computer Analysis of Fabric Supports,” Metropolitan Museum Journal 47 (2012), 99-106.

8. C. Richard Johnson Jr. and William A. Sethares, eds., Counting Vermeer: Using Weave Maps to Study Vermeer's Canvases, Appendix II: Matches (The Hague: RKD Studies, 2017), HTTPS://COUNTINGVERMEER.RKDSTUDIES.NL

9. Use of these tools is illustrated in C. Richard Johnson Jr. and William A. Sethares, "Hunting for Weave Matches: Computation in Art Scholarship," Journal of Interactive Technology and Pedagogy 12 (February 2018), HTTPS://JITP.COMMONS.GC.CUNY.EDU/HUNTING-FOR-WEAVE-MATCHESCOMPUTATION-IN-ART-SCHOLARSHIP.

10. For example, Laurens van der Maaten and Robert G. Erdmann, "Automatic Thread-Level Canvas Analysis: A Machine-Learning Approach to Analyzing the Canvas of Paintings," IEEE Signal Processing Magazine 32, no. 4 (July 2015), 38-45; and Haizhao Yang et al., "Quantitative Canvas Weave Analysis Using 2-D Synchrosqueezed Transforms: Application of Time-Frequency Analysis to Art Investigation," IEEE Signal Processing Magazine 32, no. 4 (July 2015), 55-63.

11. Paul Messier, “Image Isn't Everything: Revealing Affinities Across Collections Through the Language of the Photographic Print," Object: Photo. Modern Photographs: The Thomas Walther Collection 1909-1949, ed. Mitra Abbaspour, Lee Ann Daffner, and Maria Morris Hambourg (New York: Museum of Modern Art, 2014), 5. The report on the "Historic Photographic Paper Challenge" is described in C. Richard Johnson Jr. et al., "Pursuing Automated Classification of Historic Photographic Papers from Raking Light Images," Journal of the American Institute for Conservation 53, no. 3 (2014), 159-70.

12. Paul Messier et al., "Automated Surface Texture Classification of Inkjet and Photographic Media," Technical Program and Proceedings: NIP29: The 29th International Conference on Digital Printing Technologies (Springfield, VA: The Society for Imaging Science and Technologies, 2013), 85-91.

13. Patrice Abry, Andrew G. Klein, Paul Messier, et al., "Wove Paper Analysis through Texture Similarities," Proceedings of the 50th IEEE Annual Asilomar Conference on Signals, Systems, and Computers (ASILOMAR 2016) (Pacific Grove, CA: IEEE, 2016), 144-48.

14. For example, Allan H. Stevenson, "Chain-Indentations in Paper as Evidence," Studies in Bibliography 6 (1954), 181-95; and David Vander Meulen, “The Identification of Paper without Watermarks: The Example of Pope's 'Dunciad,"' Studies in Bibliography 37 (1984), $58-81$.

15. Item 3.2.4 in International Association of Paper Historians (hereafter IPH), "International Standard for the Registration of Papers with or without Watermarks," version 2.1.1 (2013), HTTP://WWW.PAPERHISTORY.ORG/STANDARDS/IPHN2.1.1_EN.PDF. 
16. For example, Jan C. A. van der Lubbe, Eugene P. van Someren, and Marcel J. T. Reinders, "Dating and Authentication of Rembrandt's Etchings with the Help of Computational Intelligence," in International Cultural Heritage Informatics: Proceedings from ichim01 (Milan and Pittsburgh: Archives and Museum Informatics, 2001), 485-92; and C. Richard Johnson Jr. et al., "Hunting for Paper Moldmates Among Rembrandt's Prints," IEEE Signal Processing Magazine 32, no. 4 (July 2015), 28-37.

17. Xuelie Xi, Devin Conathan, Amanda House, et al., "Automated Chain Line Marking and Pattern Matching in Radiographs of Rembrandt's Prints," Proceedings of the 50th IEEE Annual Asilomar Conference, 1-9.

18. This agrees with results from experiments on a different dataset with a different computational procedure, in Mark Van Staalduinen, "Content-Based Paper Retrieval Towards Reconstruction of Art History” (PhD diss., Delft University of Technology, 2010).

19. Counting the "number of laid lines over a distance of $20 \mathrm{~mm}$ " at various points in the paper is included as item 3.2.3 in IPH, "International Standard for the Registration of Papers with or without Watermarks."

20. Transmitted-light images have difficulty revealing the inner structural properties of paper for heavily inked artworks. They are more likely to be useful with drawings and writing, given digital image processing tools that can remove the surface images from a transmittedlight image. Examples of such tools appear in William A. Sethares, Margaret Holben Ellis, and C. Richard Johnson Jr., "Computational Watermark Enhancement in Leonardo's Codex Leicester," Journal of American Institute for Conservation 59, no. 2 (March 2020), 87-96; and Pablo Ruiz et al., "Visible Transmission Imaging of Watermarks by Suppression of Occluding Text or Drawings," Digital Applications in Archaeology and Cultural Heritage 15 (December 2019), HTTPS://DOI.ORG/10.1016/J.DAACH.2019.E00121.

21. Sara F. Gorske et al., "Moldmate Identification in 16th-Century European Paper Using Quantitative Analysis of Watermarks, Chain Line Intervals, and Laid Line Density," International Journal for Digital Art History 5 (March 3, 2021), HTTPS://DOI.ORG/10.11588/DAH.2020.5.71232.

22. Ellis and Johnson, "Computational Connoisseurship," 2; David Stone and David Stork forecast a significant impact from digital image analysis on future connoisseurship in their presentation, "Computer-Assisted Connoisseurship: The Interdisciplinary Science of Computer Vision and Image Analysis in the Study of Art," at the Third International Workshop on Image Processing for Art Investigation, The Museum of Modern Art, May 27, 2010.

23. A countermark, made in the same way as a watermark, was often added to the opposite half of the sheet to identify the papermaker, the date, quality, and function of the paper. It can sometimes be difficult to determine if the countermark is, in fact, the primary watermark.

24. IPH, "Printed Watermark Repertories," last updated February 22, 2021, HTTP://WWW.PAPERHISTORY.ORG/WATERMARK-CATALOGUEs; IPH, "Links: Online Watermark Databases/Catalogues," accessed August 4, 2021, HTTP://WWW.PAPERHISTORY.ORG/LINKS.

25. Indeed, the primary objective of Erik Hinterding's catalogue, Rembrandt as an Etcher (Ouderkerk aan den IJssel: Sound \& Vision, 2006), is to use the watermarks found in 
Rembrandt's prints to assemble a more precise chronology that sheds light on the artist's production and distribution practices.

26. Dutch University Institute for Art History, "Watermarks," accessed March 9, 2021, HTTPS://WWW.NIKI-FLORENCE.ORG/EN/ABOUT-THEINSTITUTE/RESEARCH/\%20PROJECTS/WATERMARKS.

27. Hinterding, Rembrandt as an Etcher, 1:17n18.

28. Hinterding, Rembrandt as an Etcher, 1:48.

29. Hinterding, Rembrandt as an Etcher, 2:334-35.

30. Allan H. Stevenson, "Watermarks are Twins," Studies in Bibliography 4 (1951-52), 57-91.

31. An earlier collection of an artist's watermarks in paper used for sketching and writing is Jane Roberts, A Dictionary of Michelangelo's Watermarks (Milan: Olivetti, 1988).

32. Andrew C. Weislogel and C. Richard Johnson Jr., "Decision Trees and Fruitful Collaborations: The Watermark Identification in Rembrandt's Etchings (WIRE) Project at Cornell" in Lines of Inquiry: Learning from Rembrandt's Etchings (Ithaca: Herbert F. Johnson Museum of Art, Cornell University, 2017), 32-57, HTTP://MUSEUM.CORNELL.EDU/SITES/DEFAULT/FILES/DECISIONTREESWEISLOGELJOHNSON2017-LINESOFINQUIRY.PDF; C. Richard Johnson Jr., "Decision Trees for Watermark Identification in Rembrandt's Etchings," Journal of Historians of Netherlandish Art 12, no. 2 (Summer 2020), HTTPS://JHNA.ORG/ARTICLES/DECISIONTREES-FOR-WATERMARK-IDENTIFICATION-IN-REMBRANDTS-ETCHINGS; C. Richard Johnson Jr., “The Watermark Identification in Rembrandt's Etchings (WIRE) Project at Cornell," recorded December 6, 2018 at The Frick Collection, New York, 1:50:05, HTTPS://WWW.FRICK.ORG/INTERACT/WIRE_PROJECT_CORNELL.

33. An Van Camp, "Rembrandt's Early Works on Paper," in Young Rembrandt, ed. An Van Camp, Christopher Brown, and Christiaan Vogelaar (Oxford: Ashmolean Museum, University of Oxford, 2020), 60n23.

34. Van Camp, "Rembrandt's Early Works on Paper," $61 n 28$.

35. Van Camp, "Rembrandt's Early Works on Paper," 69n75.

36. Van Camp, "Rembrandt's Early Works on Paper," 71n82.

37. These tools were created with funding from Getty Foundation Digital Art History Initiative Grant ORG-201943572, “Applying Digital Image Processing Algorithms to the Study of Prints and Drawings," May 2019-June 2021. Currently both require computer expertise no more demanding than knowledge of Adobe's Photoshop suite. Both the software and user's guides are available through an open source license now. If you would like to serve as a beta tester, please contact the second author of this article at sethares@wisc.edu or visit HTTPS://GITHUB.COM/SETHARESB/PAPERSTUDIES.

38. This step would be difficult to fully automate due to naturally occurring differences in the clarity or completeness of the two watermark images being compared; for example, one watermark image might be fragmentary or obscured by surface marks, thus preventing automatic marking by the computer. It is left up to the user to decide which precisely locatable or "tie" points to mark and their order for later alignment by the software. As will be seen in Part Two, a sequence of preselected points to mark for specific watermark types would serve as a guide for users and simplify the process even more. 
39. A screenshot is capable of capturing a still image when both watermarks are visible in their overlay. This approach was used to provide images for the examples presented in this article.

40. Nancy Ash and Shelley Fletcher, Watermarks in Rembrandt's Prints (Washington: National Gallery of Art, 1998).

41. Hinterding, Rembrandt as an Etcher, Ouderkerk aan den IJssel: Sound \& Vision, 2006)

42. Hinterding, Rembrandt as an Etcher, 2:185-86.

43. A description of the WIRE Project at Cornell is provided in Weislogel and Johnson, "Decision Trees and Fruitful Collaborations."

44. Allan H. Stevenson, "Watermarks are Twins," Studies in Bibliography 4 (1951-52), 57-91.

45. Hinterding, Rembrandt as an Etcher, 1:21-27.

46. The decision tree can be augmented, as described in Johnson, "Decision Trees for Watermark Identification in Rembrandt's Etchings," by generating new yes/no questions about features visible in the watermark fragment under consideration.

47. Discussed in C. Richard Johnson Jr. et al., "The Application of Automated Chain Line Pattern (CLiP) Matching to Identify Paper Mouldmate Candidates in Rembrandt's Prints," in Rembrandt and His Circle: Insights and Discoveries, ed. Stephanie Dickey. Amsterdam: University of Amsterdam Press, 2017, 319-34.

48. HTTPS://PEOPLE.ECE.CORNELL.EDU/JOHNSON/ANIMATION41-1-32DPI600-TVW44(SH).GIF. Discovery of this match was first cited in Johnson, "Decision Trees for Watermark Identification in Rembrandt's Etchings," n53.

49. Hinterding, Rembrandt as an Etcher, 2:185-86.

50. Thea Vignau-Wilberg, Rembrandt auf Papier: Werk und Wirkung (Hirmer: Munich, 2001), 180-81.

51. Vignau-Wilberg, Rembrandt auf Papier, 170-74.

52. Hinterding, Rembrandt as an Etcher, 2:58.

53. Leonore van Sloten, "Ferdinand Bol, the Etcher" in Ferdinand Bol and Govert Flinck: Rembrandt's Master Pupils, ed. N. Middelkoop (Zwolle: WBooks, 2017), 219-20.

54. Images of these different variations appear in Hinterding, Rembrandt as an Etcher, 3:195243.

55. Hinterding, Rembrandt as an Etcher, 2:116-37.

56. The IPH website contains a long list of printed catalogues of watermarks ("Printed Watermark Repertories," last modified February 22, 2021, HTTP://WWW.PAPERHISTORY.ORG/WATERMARK-CATALOGUES) and a separate list of links to more than twenty online catalogues ("Links: Online Watermark

Databases/Catalogues," accessed March 9, 2021, HTTP://WWW.PAPERHISTORY.ORG/LINKS), including the Bernstein Consortium's "The Memory of Paper" (last modified January 15, 2021, HTTPS://WWW.MEMORYOFPAPER.EU/BERNSTEINPORTAL), which is a well-known portal to forty-two watermark databases with more than 254,000 watermarks.

57. "LIMA: Watermark Databases," website for the Centre of the Study of the Renaissance, Warwick University, accessed January 19, 2021, HTTPS://WARWICK.AC.UK/FAC/ARTS/REN/ARCHIVE-RESEARCHOLD/LIMA/PAPER/DESCRIBING/DATABASES. 
58. For example, Mark Van Staalduinen, “Content-Based Paper Retrieval Towards Reconstruction of Art History” (PhD diss., Delft University of Technology, 2010); Plamen Doynov, "Framework for Automatic Identification of Paper Watermarks with Chain Codes" (PhD diss., University of Missouri-Kansas City, 2017); and David Picard, Thomas Henn, and Georg Dietz, "Non-Negative Dictionary Learning for Paper Watermark Similarity," Proceedings of the 50th IEEE Asilomar Conference, 133-36.

59. For example, Vinaychandran Pondenkandath et al., "Cross-Depicted Historical Motif Categorization and Retrieval with Deep Learning," Journal of Imaging 6(7), no. 71 (July 15, 2020), HTTPS://WWW.MDPI.COM/2313-433X/6/7/71; and Oumayma Bounou et al., "A Web Application for Watermark Recognition,” Journal of Data Mining and Digital Humanities 24, no. 45 (July 17, 2020), HTTPS://JDMDH.EPISCIENCES.ORG/6570.

60. Lucia P. Pardo and Giles Bergel, "Watermarks: New Ways to See and Search Them" (blog post), National Archives, London, July 30, 2020, HTTPS://BLOG.NATIONALARCHIVES.GOV.UK/WATERMARKS-NEW-WAYS-TOSEE-AND-SEARCH-THEM.

61. The images in this article are from beta-radiographs of prints by Rembrandt in the collection of the Morgan Library \& Museum in New York, the collection of radiographs of seventeenth-century Dutch prints held by the Dutch University Institute for Art History in Florence, Theo and Frans Laurentius's Watermarks 1600-1650: Found in the Zeeland Archives ('t Goy-Houten: Hes \& De Graaf, 2007), and images in Hinterding, Rembrandt as an Etcher.

62. The procedure uses three free programs that can be obtained from the second author of this article via email to sethares@wisc.edu. A description of the operation of the three programs used in this procedure is provided in Appendix 2. An explanation of the mathematics for computing the average alignment error used to rank the fit of one watermark against another appears in Appendix 3.

63. Images of these different variations appear in Hinterding, Rembrandt as an Etcher, 3:195243.

64. See HTTPS://PEOPLE.ECE.CORNELL.EDU/JOHNSON/AWI-APPENDIX1.PDF

65. Such an effort is currently underway for Hinterding's entire catalogue of Rembrandt watermarks.

66. Here "peak" includes the ball at the end of the peak.

67. Here "peak" includes the ball at the end of the peak.

68. If there is no intersection with either of the two lines forming the first collar point, this point is to be skipped, but the numbering sequence must remain intact.

69. If there is no braid, this point is to be skipped, but the numbering sequence must remain intact.

70. If there is no intersection with either of the two lines forming the fifth collar point, this point is to be skipped, but the numbering sequence must remain intact.

71. For more information on the print exhibiting this watermark, see "The Bridge at Klein Kostverloren on the Amstel," website of The Morgan Library \& Museum, accessed March 9, 2021, HTTPS://WWW.THEMORGAN.ORG/REMBRANDT/PRINT/161999. 
72. This identification is confirmed by this overlay video HTTPS://PEOPLE.ECE.CORNELL.EDU/JOHNSON/ANIMATIONF5PC-K-A-AMORGAN294(SH).GIF.

73. Hinterding, Rembrandt as an Etcher, 2:296.

74. Such discoveries of new watermarks have been made by the WIRE Project at Cornell, as noted in Weislogel and Johnson, "Decision Trees and Fruitful Collaborations, 32-57.

75. See HTTPS://PEOPLE.ECE.CORNELL.EDU/JOHNSON/AWI-APPENDIX1.PDF.

76. HTTPS://PEOPLE.ECE.CORNELL.EDU/JOHNSON/ANIMATIONEH002026-F5PC-K-E$\mathrm{A}(\mathrm{SH}) . \mathrm{GIF}$

77. Erik Hinterding, "Rembrandt and Van Vliet: The Watermark" in Rembrandt and Van Vliet: A Collaboration on Copper, ed. Christian Schuckman, Martin Royalton, and Erik Hinterding (Amsterdam: Museum het Rembrandthuis, 1996), 24-37; and Erik Hinterding, Rembrandt as an Etcher, 1:83-92.

78. Hinterding, Rembrandt as an Etcher, 2:131-32, 390-91, 416.

79. Laurentius, Watermarks 1600-1650.

80. Laurentius, Watermarks 1600-1650, 32.

81. HTTPS://PEOPLE.ECE.CORNELL.EDU/JOHNSON/ANIMATIONL483-F5PC-H-B$\mathrm{A}(\mathrm{SH})$.GIF.

82. Hinterding, Rembrandt as an Etcher, 2:124.

83. Laurentius, Watermarks 1600-1650, 34, 233, 234.

84. HTTPS://PEOPLE.ECE.CORNELL.EDU/JOHNSON/ANIMATIONL545A-F5PC-H-B$\mathrm{B}(\mathrm{SH})$.GIF.

85. Hinterding, Rembrandt as an Etcher, 2:124.

86. Frans Laurentius to first author of this article, February 22, 2021: "You will probably find many more matches with our books; over the years we found that the use of paper in the Netherlands is uniform in the 17th century. Paper used in for instance Middelburg will not differ with paper used in Amsterdam or Groningen. Rembrandt's papers are therefore a mirror of what was imported and used in Amsterdam and indeed in the Netherlands. ... In our Ostade research we also found the same watermarks, for instance."

87. HTTPS://PEOPLE.ECE.CORNELL.EDU/JOHNSON/ANIMATIONCNTRMRK-PRA_RPK-OB-248-L545B(SH).GIF.

88. Hinterding, Rembrandt as an Etcher, 2:91.

89. The computer programs described in this article are all available through an open source license. If you would like to serve as a beta tester, please contact the second author of this article at sethares@wisc.edu or visit HTTPS://GITHUB.COM/SETHARESB/PAPERSTUDIES 